\title{
Bioactive Compounds, Therapeutic Activities, and Applications of Ficus pumila L.
}

\author{
Zhi-Yong Qi ${ }^{1,2}$, Jia-Ying Zhao ${ }^{1,2}$, Fang-Jun Lin ${ }^{1,3} \mathbb{D}$, Wan-Lai Zhou ${ }^{1}$ and Ren-You Gan ${ }^{1,4, *(\mathbb{D})}$ \\ 1 Institute of Urban Agriculture, Chinese Academy of Agricultural Sciences, Chengdu 600213, China; \\ qizhiyong@caas.cn (Z.-Y.Q.); 181312024@csu.edu.cn (J.-Y.Z.); Fangjun.lin@knights.ucf.edu (F.-J.L.); \\ zhouwanlai@caas.cn (W.-L.Z.) \\ 2 School of Architecture and Art, Central South University, Changsha 410075, China \\ 3 Burnett School of Biomedical Sciences, University of Central Florida, Orlando, FL 32827, USA \\ 4 Key Laboratory of Coarse Cereal Processing (Ministry of Agriculture and Rural Affairs), School of Food and \\ Biological Engineering, Chengdu University, Chengdu 610106, China \\ * Correspondence: ganrenyou@caas.cn or ganrenyou@yahoo.com; Tel.: +86-28-80203195
}

check for updates

Citation: Qi, Z.-Y.; Zhao, J.-Y.; Lin, F.-J.; Zhou, W.-L.; Gan, R.-Y. Bioactive Compounds, Therapeutic Activities, and Applications of Ficus pumila L. Agronomy 2021, 11, 89. https:// doi.org/10.3390/agronomy11010089

Received: 2 December 2020

Accepted: 3 January 2021

Published: 5 January 2021

Publisher's Note: MDPI stays neutral with regard to jurisdictional clai$\mathrm{ms}$ in published maps and institutional affiliations.

Copyright: (C) 2021 by the authors. Licensee MDPI, Basel, Switzerland. This article is an open access article distributed under the terms and conditions of the Creative Commons Attribution (CC BY) license (https:// creativecommons.org/licenses/by/ $4.0 /)$.

\begin{abstract}
Ficus pumila L. has been used as a functional plant for a long time in East Asia, especially its fruits, as a dietary component in Japan and parts of China. A series of bioactive compounds, including phenolic acids, flavonoids, terpenoids, alcohols, and steroids, have been extracted from the stems, leaves, flowers, and fruits of Ficus pumila L. Accumulated studies have demonstrated that Ficus pumila L. has multiple therapeutic activities, including antioxidant, anti-inflammatory, antibacterial, antitumor, hypoglycemic, and cardiovascular protective effects. Moreover, Ficus pumila L. has extensive applications, such as in the food industry and ecological city construction. Herein, we summarize the latest knowledge about the bioactive compounds and therapeutic activities of Ficus pumila L., and its applications in the food industry and ecological city construction are also discussed. We hope that this comprehensive review can attract more attention to Ficus pumila L. and be helpful for its further applications.
\end{abstract}

Keywords: Ficus pumila L.; bioactive compounds; therapeutic activities; applications

\section{Introduction}

Ficus plants have a long history of human cultivation. Many Ficus species are popular foliage plants [1], and some species are commonly used in traditional medicine [2,3]. Ficus pumila L. is a creeping fig in the mulberry family (Figure 1). It is widely grown in Japan and the south of China. Plant-based natural products have been reported to have multiple biological functions that might be beneficial for human health [4-11]. The bioactive compounds, pharmacological activities, and applications of several Ficus plants, such as Ficus hispida L. [12], Ficus racemose [13], Ficus sycomorus [14], Ficus religiosa [15], and Ficus carica L. [16,17], have been discussed recently. Ficus pumila L. also exhibits many therapeutic activities, including antioxidant [18], anti-inflammatory [19], antibacterial [20], anti-cancer [21], blood sugar lowering [22], gastrointestinal protection [23], hepatorenal protection [24], and cardiovascular protection [25]. The biological functions of Ficus pumila L. are mainly attributed to the bioactive compounds in different parts of Ficus pumila L. The bioactive compounds found in Ficus pumila L. include different types, especially flavonoids, terpenes, alcohols, steroids, and phenolic acids. In order to better understand Ficus pumila L., we thoroughly summarized the latest knowledge about Ficus pumila L., including its bioactive compounds, therapeutic activities, and potential applications in the food industry and ecological restoration. 


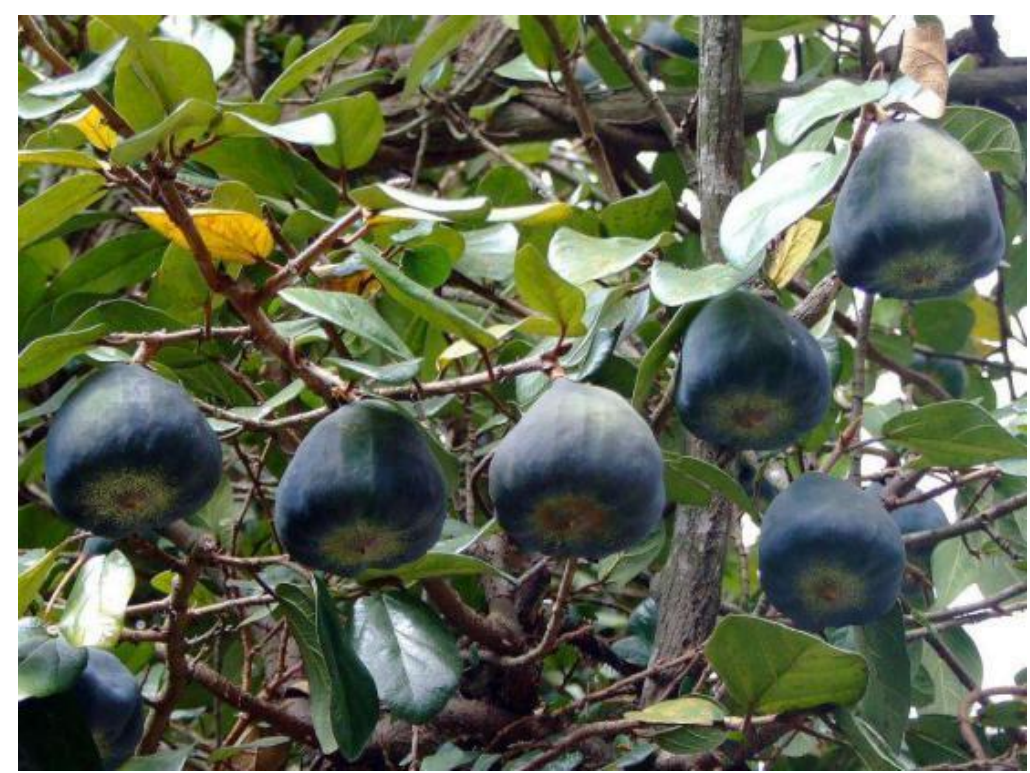

Figure 1. Stems, leaves, and fruits of Ficus pumila L.

\section{Bioactive Compounds in Ficus pumila L.}

\subsection{Flavonoids}

So far, thirty-seven flavonoids (Table 1) have been identified in Ficus pumila L. The leaves and inflorescences of Ficus pumila L. have the highest flavonoid contents. In addition, the contents of flavonoids in leaves are significantly higher than those in stems and seeds [26].

Table 1. Flavonoid compounds found in Ficus pumila L.

\begin{tabular}{|c|c|c|c|c|c|c|c|}
\hline No. & Compounds & $\begin{array}{l}\text { Molecular } \\
\text { Formula }\end{array}$ & Plant Parts & $\begin{array}{l}\text { Extraction } \\
\text { Solvents }\end{array}$ & $\begin{array}{l}\text { Extraction } \\
\text { Methods }\end{array}$ & $\begin{array}{l}\text { Detection } \\
\text { Methods }\end{array}$ & Ref. \\
\hline 1 & $\begin{array}{c}5,7,2^{\prime}, 5^{\prime}- \\
\text { Tetrahydroxyflavanone }\end{array}$ & $\mathrm{C}_{15} \mathrm{H}_{10} \mathrm{O}_{6}$ & $\begin{array}{l}\text { Stem and } \\
\text { leaf }\end{array}$ & $\begin{array}{c}\mathrm{CHCl}_{3} / \text { Methanol } \\
9: 1\end{array}$ & $\begin{array}{c}\text { Liquid } \\
\text { extraction }\end{array}$ & NMR & [27] \\
\hline 2 & $\begin{array}{l}5,7,2^{\prime} \text {-Trihydroxy- } 4^{\prime}- \\
\text { methoxyisoflavone }\end{array}$ & $\mathrm{C}_{16} \mathrm{H}_{12} \mathrm{O}_{6}$ & Stem & $80 \%$ Ethanol & $\begin{array}{l}\text { Liquid } \\
\text { extraction }\end{array}$ & $\begin{array}{c}{ }^{1} \mathrm{H} \text {-and } \\
{ }^{13} \mathrm{C}-\mathrm{NMR}\end{array}$ & [28] \\
\hline 3 & $\begin{array}{l}\text { 5,7, } 4^{\prime} \text {-Trimethoxy } \\
\text { flavane-3-ol }\end{array}$ & $\mathrm{C}_{18} \mathrm{H}_{20} \mathrm{O}_{5}$ & $\begin{array}{l}\text { Aboveground } \\
\text { parts } \\
\text { except fruit }\end{array}$ & $75 \%$ Ethanol & $\begin{array}{l}\text { Liquid } \\
\text { extraction }\end{array}$ & $\begin{array}{c}{ }^{1} \mathrm{H} \text {-and } \\
{ }^{13} \mathrm{C}-\mathrm{NMR}, \mathrm{EI}-\mathrm{MS}\end{array}$ & [29] \\
\hline 4 & $\begin{array}{l}\text { 5,7,4'-Trihydroxy-3'-(2- } \\
\text { hydroxy-3-methyl-3- } \\
\text { butenyl)-isoflavone }\end{array}$ & $\mathrm{C}_{20} \mathrm{H}_{18} \mathrm{O}_{6}$ & Stem & $80 \%$ Ethanol & $\begin{array}{l}\text { Liquid } \\
\text { extraction }\end{array}$ & $\begin{array}{c}{ }^{1} \mathrm{H} \text {-and } \\
{ }^{13} \mathrm{C}-\mathrm{NMR}\end{array}$ & [28] \\
\hline 5 & $\begin{array}{l}\text { 5,7, } 4^{\prime} \text {-Trihydroxy-3'-(3- } \\
\text { hydroxy-3- } \\
\text { methylbutyl)isoflavone }\end{array}$ & $\mathrm{C}_{20} \mathrm{H}_{20} \mathrm{O}_{6}$ & Stem & $80 \%$ Ethanol & $\begin{array}{l}\text { Liquid } \\
\text { extraction }\end{array}$ & $\begin{array}{c}{ }^{1} \mathrm{H} \text {-and } \\
{ }^{13} \mathrm{C}-\mathrm{NMR}\end{array}$ & [28] \\
\hline 6 & $\begin{array}{c}5,7,4^{\prime}- \\
\text { Trihydroxyisoflavone }\end{array}$ & $\mathrm{C}_{15} \mathrm{H}_{10} \mathrm{O}_{5}$ & Stem & $80 \%$ Ethanol & $\begin{array}{l}\text { Liquid } \\
\text { extraction }\end{array}$ & $\begin{array}{c}{ }^{1} \mathrm{H} \text {-and } \\
{ }^{13} \mathrm{C}-\mathrm{NMR}\end{array}$ & [28] \\
\hline 7 & 5,7-Dihydroxy chromone & $\mathrm{C}_{9} \mathrm{H}_{6} \mathrm{O}_{4}$ & Stem & $80 \%$ Ethanol & $\begin{array}{c}\text { Liquid } \\
\text { extraction }\end{array}$ & $\begin{array}{c}{ }^{1} \mathrm{H} \text {-and } \\
{ }^{13} \mathrm{C}-\mathrm{NMR}\end{array}$ & [28] \\
\hline 8 & $\begin{array}{l}\text { 7,4'-Dimethoxy-5- } \\
\text { hydroxyisoflavone }\end{array}$ & $\mathrm{C}_{17} \mathrm{H}_{14} \mathrm{O}_{5}$ & $\begin{array}{l}\text { Stem and } \\
\text { leaf }\end{array}$ & $\begin{array}{c}\mathrm{CHCl}_{3} / \text { Methanol } \\
9: 1\end{array}$ & $\begin{array}{l}\text { Liquid } \\
\text { extraction }\end{array}$ & $\begin{array}{c}{ }^{1} \mathrm{H} \text {-and } \\
{ }^{13} \mathrm{C}-\mathrm{NMR}\end{array}$ & [27] \\
\hline 9 & Alpinum isoflavone & $\mathrm{C}_{20} \mathrm{H}_{16} \mathrm{O}_{5}$ & Stem & $80 \%$ Ethanol & $\begin{array}{l}\text { Liquid } \\
\text { extraction }\end{array}$ & $\begin{array}{c}{ }^{1} \mathrm{H} \text {-and } \\
{ }^{13} \mathrm{C}-\mathrm{NMR}\end{array}$ & [28] \\
\hline
\end{tabular}


Table 1. Cont.

\begin{tabular}{|c|c|c|c|c|c|c|c|}
\hline No. & Compounds & $\begin{array}{l}\text { Molecular } \\
\text { Formula }\end{array}$ & Plant Parts & $\begin{array}{l}\text { Extraction } \\
\text { Solvents }\end{array}$ & $\begin{array}{l}\text { Extraction } \\
\text { Methods }\end{array}$ & $\begin{array}{l}\text { Detection } \\
\text { Methods }\end{array}$ & Ref. \\
\hline 10 & Apigenin & $\mathrm{C}_{15} \mathrm{H}_{10} \mathrm{O}_{5}$ & $\begin{array}{l}\text { Stem, leaf, } \\
\text { and above } \\
\text { ground } \\
\text { parts } \\
\text { except fruit }\end{array}$ & $\begin{array}{c}\text { 80\% Ethanol, } \\
\text { 75\% Ethanol, } \\
\mathrm{CHCl}_{3} / \text { Methanol } \\
\text { 9:1 }\end{array}$ & $\begin{array}{c}\text { Liquid } \\
\text { extraction }\end{array}$ & $\begin{array}{c}{ }^{1} \mathrm{H} \text {-and } \\
{ }^{13} \mathrm{C}-\mathrm{NMR}\end{array}$ & [27-29] \\
\hline 11 & $\begin{array}{l}\text { Apigenin } \\
\text { 6-neohesperidose }\end{array}$ & $\mathrm{C}_{27} \mathrm{H}_{30} \mathrm{O}_{14}$ & Leaf & Methanol & $\begin{array}{c}\text { Liquid } \\
\text { extraction }\end{array}$ & HPLC, NMR & [30] \\
\hline 12 & Astragalin & $\mathrm{C}_{21} \mathrm{H}_{20} \mathrm{O}_{11}$ & $\begin{array}{l}\text { Inflorescence } \\
\text { receptacle, } \\
\text { fresh leaves }\end{array}$ & $\begin{array}{l}\text { Methanol, 75\% } \\
\text { industrial } \\
\text { ethanol }\end{array}$ & $\begin{array}{c}\text { Liquid } \\
\text { extraction }\end{array}$ & HPLC, NMR & [31-33] \\
\hline 13 & Catechin & $\mathrm{C}_{15} \mathrm{H}_{14} \mathrm{O}_{6}$ & $\begin{array}{l}\text { Stem, } \\
\text { above } \\
\text { ground } \\
\text { parts } \\
\text { except fruit }\end{array}$ & $\begin{array}{l}80 \% \text { Ethanol, } \\
75 \% \text { industrial } \\
\text { ethanol }\end{array}$ & $\begin{array}{c}\text { Liquid } \\
\text { extraction }\end{array}$ & $\begin{array}{l}{ }^{1} \mathrm{H} \text {-and } \\
{ }^{13} \mathrm{C}-\mathrm{NMR}, \\
\text { ESI-MS }\end{array}$ & {$[28,29,34]$} \\
\hline 14 & Chrysin & $\mathrm{C}_{15} \mathrm{H}_{10} \mathrm{O}_{4}$ & $\begin{array}{l}\text { Stem and } \\
\text { leaf }\end{array}$ & $\begin{array}{c}\mathrm{CHCl}_{3} / \text { Methanol } \\
9: 1\end{array}$ & $\begin{array}{c}\text { Liquid } \\
\text { extraction }\end{array}$ & NMR & [27] \\
\hline 15 & Chrysoeriol & $\mathrm{C}_{16} \mathrm{H}_{12} \mathrm{O}_{6}$ & Stem & $80 \%$ Ethanol & $\begin{array}{c}\text { Liquid } \\
\text { extraction }\end{array}$ & $\begin{array}{c}{ }^{1} \mathrm{H} \text {-and } \\
{ }^{13} \mathrm{C}-\mathrm{NMR}\end{array}$ & [28] \\
\hline 16 & Derrone & $\mathrm{C}_{20} \mathrm{H}_{16} \mathrm{O}_{5}$ & Stem & $80 \%$ Ethanol & $\begin{array}{c}\text { Liquid } \\
\text { extraction }\end{array}$ & $\begin{array}{c}{ }^{1} \mathrm{H} \text {-and } \\
{ }^{13} \mathrm{C}-\mathrm{NMR}\end{array}$ & [28] \\
\hline 17 & $\begin{array}{l}\text { Dihydrokaempferol 5-O- } \\
\beta \text {-D-glucopyranoside }\end{array}$ & $\mathrm{C}_{21} \mathrm{H}_{22} \mathrm{O}_{11}$ & $\begin{array}{l}\text { Inflorescence } \\
\text { receptacle }\end{array}$ & 95\% Ethanol & $\begin{array}{l}\text { Diafiltration } \\
\text { extraction }\end{array}$ & $\begin{array}{c}\text { Silica gel, } \\
\text { Sephadex LH-20, } \\
\text { ODS, and } \\
\text { preparative } \\
\text { HPLC column } \\
\text { chromatographies }\end{array}$ & [35] \\
\hline 18 & $\begin{array}{l}\text { Dihydrokaempferol 7-O- } \\
\beta \text {-D-glucopyranoside }\end{array}$ & $\mathrm{C}_{21} \mathrm{H}_{22} \mathrm{O}_{11}$ & $\begin{array}{l}\text { Inflorescence } \\
\text { receptacle }\end{array}$ & 95\% Ethanol & $\begin{array}{l}\text { Diafiltration } \\
\text { extraction }\end{array}$ & $\begin{array}{c}\text { Silica gel, } \\
\text { Sephadex LH-20, } \\
\text { ODS, and } \\
\text { preparative } \\
\text { HPLC column } \\
\text { chromatographies }\end{array}$ & [35] \\
\hline 19 & Epicatechin & $\mathrm{C}_{15} \mathrm{H}_{14} \mathrm{O}_{6}$ & $\begin{array}{l}\text { Above } \\
\text { ground } \\
\text { parts } \\
\text { except fruit }\end{array}$ & $\begin{array}{l}75 \% \text { industrial } \\
\text { ethanol }\end{array}$ & $\begin{array}{l}\text { Liquid } \\
\text { extraction }\end{array}$ & $\begin{array}{c}{ }^{1} \mathrm{H} \text {-and } \\
{ }^{13} \mathrm{C}-\mathrm{NMR}\end{array}$ & [29] \\
\hline 20 & Eriodictyol & $\mathrm{C}_{15} \mathrm{H}_{12} \mathrm{O}_{6}$ & Stem & $80 \%$ Ethanol & $\begin{array}{c}\text { Liquid } \\
\text { extraction }\end{array}$ & $\begin{array}{c}{ }^{1} \mathrm{H} \text {-and } \\
{ }^{13} \mathrm{C}-\mathrm{NMR}\end{array}$ & [28] \\
\hline 21 & Ficuisoflavone & $\mathrm{C}_{20} \mathrm{H}_{16} \mathrm{O}_{6}$ & Stem & $80 \%$ Ethanol & $\begin{array}{c}\text { Liquid } \\
\text { extraction }\end{array}$ & $\begin{array}{c}{ }^{1} \mathrm{H} \text {-and } \\
{ }^{13} \mathrm{C}-\mathrm{NMR}\end{array}$ & [28] \\
\hline 22 & Genistein & $\mathrm{C}_{15} \mathrm{H}_{10} \mathrm{O}_{5}$ & $\begin{array}{l}\text { Stem and } \\
\text { leaf }\end{array}$ & $\begin{array}{c}\mathrm{CHCl}_{3} / \text { Methanol } \\
9: 1\end{array}$ & $\begin{array}{c}\text { Liquid } \\
\text { extraction }\end{array}$ & NMR & [27] \\
\hline 23 & Hesperitin & $\mathrm{C}_{16} \mathrm{H}_{14} \mathrm{O}_{6}$ & $\begin{array}{l}\text { Stem and } \\
\text { leaf }\end{array}$ & $\begin{array}{c}\mathrm{CHCl}_{3} / \text { Methanol } \\
9: 1\end{array}$ & $\begin{array}{c}\text { Liquid } \\
\text { extraction }\end{array}$ & NMR & [27] \\
\hline 24 & Isoquercitrin & $\mathrm{C}_{21} \mathrm{H}_{20} \mathrm{O}_{12}$ & $\begin{array}{l}\text { Inflorescence } \\
\text { receptacle, } \\
\text { fresh leaves }\end{array}$ & $\begin{array}{l}\text { Methanol, 75\% } \\
\text { industrial } \\
\text { ethanol }\end{array}$ & $\begin{array}{l}\text { Diafiltration } \\
\text { extraction }\end{array}$ & $\begin{array}{c}\text { Silica gel, } \\
\text { Sephadex LH-20, } \\
\text { ODS, and } \\
\text { preparative } \\
\text { HPLC column } \\
\text { chromatographies }\end{array}$ & {$[31,32,35]$} \\
\hline
\end{tabular}


Table 1. Cont.

\begin{tabular}{|c|c|c|c|c|c|c|c|}
\hline No. & Compounds & $\begin{array}{l}\text { Molecular } \\
\text { Formula }\end{array}$ & Plant Parts & $\begin{array}{l}\text { Extraction } \\
\text { Solvents }\end{array}$ & $\begin{array}{l}\text { Extraction } \\
\text { Methods }\end{array}$ & $\begin{array}{l}\text { Detection } \\
\text { Methods }\end{array}$ & Ref. \\
\hline 25 & $\begin{array}{l}\text { Isoquercitrin } 6-\mathrm{C} \text { a-L- } \\
\text { rhamnopyranosyl- }(1 \rightarrow 2)- \\
\beta \text {-D-glucopyranoside }\end{array}$ & $\mathrm{C}_{33} \mathrm{H}_{41} \mathrm{O}_{20}$ & Leaf & Methanol & $\begin{array}{l}\text { Liquid } \\
\text { extraction }\end{array}$ & NMR & [32] \\
\hline 26 & $\begin{array}{l}\text { Isorhamnetin-3-O- } \\
\text { glucoside }\end{array}$ & $\mathrm{C}_{22} \mathrm{H}_{22} \mathrm{O}_{12}$ & $\begin{array}{l}\text { Stem and } \\
\text { leaf }\end{array}$ & $\begin{array}{c}\mathrm{CHCl}_{3} / \text { Methanol } \\
9: 1\end{array}$ & $\begin{array}{l}\text { Liquid } \\
\text { extraction }\end{array}$ & NMR & [27] \\
\hline 27 & $\begin{array}{l}\text { Kaempferol 3-O-a-L- } \\
\text { rhamnopyranosyl } \\
(1 \rightarrow 6)-\beta \text {-D- } \\
\text { glucopyranoside }\end{array}$ & $\mathrm{C}_{27} \mathrm{H}_{30} \mathrm{O}_{15}$ & $\begin{array}{l}\text { Inflorescence } \\
\text { receptacle, } \\
\text { leaf, and } \\
\text { fruit }\end{array}$ & $\begin{array}{l}\text { Ethanol and } \\
\text { methanol }\end{array}$ & $\begin{array}{l}\text { Diafiltration } \\
\text { extraction }\end{array}$ & $\begin{array}{c}\text { Silica gel, } \\
\text { Sephadex LH-20, } \\
\text { ODS, and } \\
\text { preparative } \\
\text { HPLC column } \\
\text { chromatographies }\end{array}$ & $\begin{array}{c}{[30,32,35,} \\
36]\end{array}$ \\
\hline 28 & $\begin{array}{l}\text { Kaempferol } \\
\text { 3-robinobioside }\end{array}$ & $\mathrm{C}_{27} \mathrm{H}_{30} \mathrm{O}_{15}$ & Leaf & Methanol & $\begin{array}{c}\text { Liquid } \\
\text { extraction }\end{array}$ & HPLC, NMR & {$[30,32]$} \\
\hline 29 & Lupin isoflavone $C$ & $\mathrm{C}_{20} \mathrm{H}_{18} \mathrm{O}_{6}$ & Stem & $80 \%$ Ethanol & $\begin{array}{c}\text { Liquid } \\
\text { extraction }\end{array}$ & $\begin{array}{c}{ }^{1} \mathrm{H} \text {-and } \\
{ }^{13} \mathrm{C}-\mathrm{NMR}\end{array}$ & [28] \\
\hline 30 & Luteolin & $\mathrm{C}_{15} \mathrm{H}_{10} \mathrm{O}_{6}$ & $\begin{array}{l}\text { Stem and } \\
\text { leaf }\end{array}$ & $\begin{array}{c}\mathrm{CHCl}_{3} / \text { Methanol } \\
9: 1\end{array}$ & $\begin{array}{l}\text { Liquid } \\
\text { extraction }\end{array}$ & NMR & [27] \\
\hline 31 & $\begin{array}{l}\text { Maesopsin 6-O- } \beta \text {-D- } \\
\text { glucopyranoside }\end{array}$ & $\mathrm{C}_{21} \mathrm{H}_{22} \mathrm{O}_{11}$ & $\begin{array}{l}\text { Inflorescence } \\
\text { receptacle }\end{array}$ & $95 \%$ Ethanol & $\begin{array}{l}\text { Diafiltration } \\
\text { extraction }\end{array}$ & $\begin{array}{c}\text { Silica gel, } \\
\text { Sephadex LH-20, } \\
\text { ODS, and } \\
\text { preparative } \\
\text { HPLC column } \\
\text { chromatographies }\end{array}$ & [35] \\
\hline
\end{tabular}

\begin{tabular}{|c|c|c|c|c|c|c|c|}
\hline 32 & Naringenin & $\mathrm{C}_{15} \mathrm{H}_{12} \mathrm{O}_{5}$ & $\begin{array}{c}\text { Above } \\
\text { ground } \\
\text { parts } \\
\text { except fruit, } \\
\text { stem, and } \\
\text { leaf }\end{array}$ & $\begin{array}{c}80 \% \text { Ethanol, } \\
75 \% \text { industrial } \\
\text { ethanol, } \\
\mathrm{CHCl}_{3} / \text { methanol } \\
9: 1\end{array}$ & $\begin{array}{c}\text { Liquid } \\
\text { extraction }\end{array}$ & $\begin{array}{c}{ }^{1} \mathrm{H} \text {-and } \\
{ }^{13} \mathrm{C}-\mathrm{NMR}\end{array}$ & [27-29] \\
\hline 33 & Quercetin & $\mathrm{C}_{15} \mathrm{H}_{10} \mathrm{O}_{7}$ & $\begin{array}{l}\text { Above } \\
\text { ground } \\
\text { parts } \\
\text { except fruit }\end{array}$ & 75\% Ethanol & $\begin{array}{c}\text { Liquid } \\
\text { extraction }\end{array}$ & $\begin{array}{c}{ }^{1} \mathrm{H} \text {-and } \\
{ }^{13} \mathrm{C}-\mathrm{NMR}\end{array}$ & {$[18,29,37]$} \\
\hline 34 & Quercitrin & $\mathrm{C}_{21} \mathrm{H}_{20} \mathrm{O}_{11}$ & $\begin{array}{c}\text { Fruit, stem, } \\
\text { and leaf }\end{array}$ & $\begin{array}{l}95 \% \text { Ethanol, } \\
\text { petroleum ether, } \\
\text { ethyl acetate, } \\
\text { and N-butanol }\end{array}$ & $\begin{array}{c}\text { Diafiltration } \\
\text { extraction }\end{array}$ & $\begin{array}{c}\text { Silica gel, } \\
\text { Sephadex LH-20, } \\
\text { ODS, and } \\
\text { preparative } \\
\text { HPLC column } \\
\text { chromatographies }\end{array}$ & {$[27,31]$} \\
\hline 35 & Rutin & $\mathrm{C}_{27} \mathrm{H}_{30} \mathrm{O}_{16}$ & $\begin{array}{l}\text { Leaf, stem, } \\
\text { fruit, inflo- } \\
\text { rescence } \\
\text { receptacle }\end{array}$ & $\begin{array}{c}\text { Methanol, } \\
\text { ethanol, } \\
\mathrm{CHCl}_{3} / \text { methanol } \\
9: 1\end{array}$ & $\begin{array}{c}\text { Liquid } \\
\text { extraction }\end{array}$ & $\begin{array}{c}{ }^{1} \mathrm{H} \text {-and } \\
{ }^{13} \mathrm{C}-\mathrm{NMR}\end{array}$ & $\begin{array}{l}{[19,30,31,} \\
33,35,38]\end{array}$ \\
\hline 36 & Taxifolin & $\mathrm{C}_{15} \mathrm{H}_{12} \mathrm{O}_{7}$ & $\begin{array}{l}\text { Stem and } \\
\text { leaf }\end{array}$ & $\begin{array}{c}\mathrm{CHCl}_{3} / \text { methanol } \\
9: 1\end{array}$ & $\begin{array}{l}\text { Liquid } \\
\text { extraction }\end{array}$ & NMR & [27] \\
\hline 37 & Tricetin & $\mathrm{C}_{15} \mathrm{H}_{10} \mathrm{O}_{7}$ & $\begin{array}{c}\text { Stem and } \\
\text { leaf }\end{array}$ & $\begin{array}{c}\mathrm{CHCl}_{3} / \text { methanol } \\
9: 1\end{array}$ & $\begin{array}{c}\text { Liquid } \\
\text { extraction }\end{array}$ & NMR & [27] \\
\hline
\end{tabular}

Abbreviations: NMR, nuclear magnetic resonance spectroscopy; HPLC, high performance liquid chromatography; ESI-MS, electrospray ionization-mass spectrometry; ODS, octadecylsilyl. 


\subsection{Phenolic Acids and Their Derivatives}

There have been 12 phenolic acids (Table 2) isolated from Ficus pumila L., four of which are phenylpropanoid compounds (9-12). Most of the phenolic acids and their derivatives are found in the inflorescence and receptacle of Ficus pumila L.

Table 2. Phenolic acids and their derivatives found in Ficus pumila L.

\begin{tabular}{|c|c|c|c|c|c|c|c|}
\hline No. & Compounds & $\begin{array}{l}\text { Molecular } \\
\text { Formula }\end{array}$ & Plant Parts & $\begin{array}{l}\text { Extraction } \\
\text { Solvents }\end{array}$ & $\begin{array}{l}\text { Extraction } \\
\text { Methods }\end{array}$ & $\begin{array}{l}\text { Detection } \\
\text { Methods }\end{array}$ & Ref. \\
\hline 1 & $\begin{array}{c}\text { 4-Acetonyl-3,5- } \\
\text { dimethoxy- } p \text {-quinol }\end{array}$ & $\mathrm{C}_{11} \mathrm{H}_{14} \mathrm{O}_{5}$ & $\begin{array}{l}\text { Inflorescence } \\
\text { receptacle }\end{array}$ & $95 \%$ Ethanol & $\begin{array}{c}\text { Liquid } \\
\text { extraction }\end{array}$ & $\begin{array}{c}{ }^{1} \mathrm{H} \text {-and } \\
{ }^{13} \mathrm{C}-\mathrm{NMR}\end{array}$ & [35] \\
\hline 2 & $\begin{array}{l}\text { 5-O-Caffeoyl quinic } \\
\text { acid butyl ester }\end{array}$ & $\mathrm{C}_{20} \mathrm{H}_{26} \mathrm{O}_{9}$ & $\begin{array}{l}\text { Inflorescence } \\
\text { receptacle }\end{array}$ & 95\% Ethanol & $\begin{array}{l}\text { Diafiltration } \\
\text { extraction }\end{array}$ & $\begin{array}{c}\text { Silica gel, } \\
\text { Sephadex LH-20, } \\
\text { ODS, and } \\
\text { preparative } \\
\text { HPLC column } \\
\text { chromatographies }\end{array}$ & [35] \\
\hline 3 & $\begin{array}{l}\text { 5-O-Caffeoyl quinic } \\
\text { acid methyl ester }\end{array}$ & $\mathrm{C}_{17} \mathrm{H}_{20} \mathrm{O}_{9}$ & $\begin{array}{l}\text { Inflorescence } \\
\text { receptacle }\end{array}$ & $95 \%$ Ethanol & $\begin{array}{l}\text { Diafiltration } \\
\text { extraction }\end{array}$ & $\begin{array}{c}\text { Silica gel, } \\
\text { Sephadex LH-20, } \\
\text { ODS, and } \\
\text { preparative } \\
\text { HPLC column } \\
\text { chromatographies }\end{array}$ & [35] \\
\hline 4 & Bergapten & $\mathrm{C}_{12} \mathrm{H}_{8} \mathrm{O}_{4}$ & Stem, leaf & $\begin{array}{c}80 \% \text { Ethanol, } \\
\mathrm{CHCl}_{3} / \text { methanol } \\
9: 1\end{array}$ & $\begin{array}{l}\text { Liquid } \\
\text { extraction }\end{array}$ & $\begin{array}{c}{ }^{1} \mathrm{H} \text {-and } \\
{ }^{13} \mathrm{C}-\mathrm{NMR}\end{array}$ & {$[28,36,38,39]$} \\
\hline 5 & Caffeic acid & $\mathrm{C}_{9} \mathrm{H}_{8} \mathrm{O}_{4}$ & $\begin{array}{l}\text { Inflorescence } \\
\text { receptacle }\end{array}$ & 95\% Ethanol & $\begin{array}{l}\text { Diafiltration } \\
\text { extraction }\end{array}$ & $\begin{array}{c}\text { Silica gel, } \\
\text { Sephadex LH-20, } \\
\text { ODS, and } \\
\text { preparative } \\
\text { HPLC column } \\
\text { chromatographies }\end{array}$ & [35] \\
\hline 6 & Chlorogenic acid & $\mathrm{C}_{16} \mathrm{H}_{18} \mathrm{O}_{9}$ & $\begin{array}{l}\text { Inflorescence } \\
\text { receptacle }\end{array}$ & 95\% Ethanol & $\begin{array}{l}\text { Diafiltration } \\
\text { extraction }\end{array}$ & $\begin{array}{c}\text { Silica gel, } \\
\text { Sephadex LH-20, } \\
\text { ODS, and } \\
\text { preparative } \\
\text { HPLC column } \\
\text { chromatographies }\end{array}$ & [35] \\
\hline 7 & $\begin{array}{c}\text { Oxypeucedanin } \\
\text { hydrate }\end{array}$ & $\mathrm{C}_{17} \mathrm{H}_{18} \mathrm{O}_{6}$ & Leaf & Ethanol & $\begin{array}{c}\text { Liquid } \\
\text { extraction }\end{array}$ & NMR & [39] \\
\hline 8 & Protocatechuic acid & $\mathrm{C}_{7} \mathrm{H}_{6} \mathrm{O}_{4}$ & $\begin{array}{l}\text { Inflorescence } \\
\text { receptacle }\end{array}$ & 95\% Ethanol & $\begin{array}{l}\text { Diafiltration } \\
\text { extraction }\end{array}$ & $\begin{array}{c}\text { Silica gel, } \\
\text { Sephadex LH-20, } \\
\text { ODS, and } \\
\text { preparative } \\
\text { HPLC column } \\
\text { chromatographies }\end{array}$ & [35] \\
\hline 9 & Psoralene & $\mathrm{C}_{11} \mathrm{H}_{6} \mathrm{O}_{3}$ & Fruit & Methanol & $\begin{array}{l}\text { Liquid } \\
\text { extraction }\end{array}$ & $\begin{array}{c}\text { FAB-MS, }{ }^{1} \mathrm{H}-{ }^{13} \mathrm{C}- \\
\text { and }{ }^{13} \mathrm{C}-{ }^{1} \mathrm{H} \\
\text { COSY NMR }\end{array}$ & {$[36,38]$} \\
\hline 10 & $\begin{array}{l}p \text {-Hydroxybenzoic } \\
\text { acid }\end{array}$ & $\mathrm{C}_{7} \mathrm{H}_{6} \mathrm{O}_{3}$ & $\begin{array}{l}\text { Inflorescence } \\
\text { receptacle }\end{array}$ & 95\% Ethanol & $\begin{array}{l}\text { Diafiltration } \\
\text { extraction }\end{array}$ & $\begin{array}{c}\text { Silica gel, } \\
\text { Sephadex LH-20, } \\
\text { ODS, and } \\
\text { preparative } \\
\text { HPLC column } \\
\text { chromatographies }\end{array}$ & [35] \\
\hline
\end{tabular}


Table 2. Cont.

\begin{tabular}{|c|c|c|c|c|c|c|c|}
\hline No. & Compounds & $\begin{array}{l}\text { Molecular } \\
\text { Formula }\end{array}$ & Plant Parts & $\begin{array}{l}\text { Extraction } \\
\text { Solvents }\end{array}$ & $\begin{array}{l}\text { Extraction } \\
\text { Methods }\end{array}$ & $\begin{array}{l}\text { Detection } \\
\text { Methods }\end{array}$ & Ref. \\
\hline 11 & $\begin{array}{c}\text { Seco-isolariciresinol } \\
\text { 9-O- } \beta \text {-D- } \\
\text { glucopyranoside }\end{array}$ & $\mathrm{C}_{26} \mathrm{H}_{34} \mathrm{O}_{11}$ & $\begin{array}{l}\text { Inflorescence } \\
\text { receptacle }\end{array}$ & 95\% Ethanol & $\begin{array}{c}\text { Diafiltration } \\
\text { extraction }\end{array}$ & $\begin{array}{c}\text { Silica gel, } \\
\text { Sephadex LH-20, } \\
\text { ODS, and } \\
\text { preparative } \\
\text { HPLC column } \\
\text { chromatographies }\end{array}$ & [35] \\
\hline 12 & Vanillic acid & $\mathrm{C}_{8} \mathrm{H}_{8} \mathrm{O}_{4}$ & $\begin{array}{l}\text { Inflorescence } \\
\text { receptacle }\end{array}$ & 95\% Ethanol & $\begin{array}{c}\text { Diafiltration } \\
\text { extraction }\end{array}$ & $\begin{array}{c}\text { Silica gel, } \\
\text { Sephadex LH-20, } \\
\text { ODS, and } \\
\text { preparative } \\
\text { HPLC column } \\
\text { chromatographies }\end{array}$ & [35] \\
\hline
\end{tabular}

Abbreviations: ODS, octadecylsilyl; HPLC, high performance liquid chromatography; NMR, nuclear magnetic resonance spectroscopy; COSY, correlated spectroscopy.

\subsection{Terpenoids}

Triterpenoids have multiple pharmacological effects, such as immunoregulatory, antitumor, liver protection, and blood lipid-lowering effects. At present, 54 terpenoids (Table 3), mainly triterpenes and sesquiterpenes, have been isolated from Ficus pumila L., of which 25 are sesquiterpenes, mainly distributed in the stems, leaves, and fruits. In addition, there are 29 triterpenoids found in Ficus pumila L., which can be divided into oleanane type, ursane type, lupane type, dammarane type, lanostane, and cyclortane according to their skeleton structure [36].

Table 3. Terpenoids found in Ficus pumila L.

\begin{tabular}{|c|c|c|c|c|c|c|c|}
\hline No. & Compounds & $\begin{array}{l}\text { Molecular } \\
\text { Formula }\end{array}$ & Plant Parts & $\begin{array}{c}\text { Extraction } \\
\text { Solvents }\end{array}$ & $\begin{array}{l}\text { Extraction } \\
\text { Methods }\end{array}$ & $\begin{array}{l}\text { Detection } \\
\text { Methods }\end{array}$ & Ref. \\
\hline 1 & $\begin{array}{c}\left(1^{\prime} \mathrm{S}, 6^{\prime} \mathrm{R}\right)-8^{\prime}- \\
\text { Hydroxyabscisic acid } \\
\beta \text {-D-glucoside }\end{array}$ & $\mathrm{C}_{21} \mathrm{H}_{30} \mathrm{O}_{10}$ & $\begin{array}{l}\text { Inflorescence } \\
\text { receptacle, } \\
\text { fruit }\end{array}$ & $\begin{array}{l}\text { 95\%Ethanol, } \\
\text { methanol }\end{array}$ & $\begin{array}{c}\text { Diafiltration } \\
\text { extraction }\end{array}$ & $\begin{array}{c}\text { Silica gel, } \\
\text { Sephadex LH-20, } \\
\text { ODS, preparative } \\
\text { HPLC column, } \\
\text { chromatogra- } \\
\text { phies }\end{array}$ & {$[32,35,36]$} \\
\hline 2 & $\begin{array}{c}\text { (1S,4S,5R,6R,7S,10S)- } \\
\text { 1,4,6-Trihydroxy } \\
\text { eucalyptane6-O- } \beta \text {-D- } \\
\text { glucopyranoside }\end{array}$ & $\mathrm{C}_{21} \mathrm{H}_{38} \mathrm{O}_{8}$ & Fruit & Methanol & $\begin{array}{c}\text { Liquid } \\
\text { extraction }\end{array}$ & $\begin{array}{c}\text { FAB-MS, }{ }^{1} \mathrm{H}-{ }^{13} \mathrm{C}- \\
\text { and }{ }^{13} \mathrm{C}-{ }^{1} \mathrm{H} \\
\text { COSY NMR }\end{array}$ & {$[36,38]$} \\
\hline 3 & $\begin{array}{c}\text { (1S,4S,5S,6R,7R,10S)- } \\
\text { 1,4-Trihydroxyolane1- } \\
\text { O- } \beta \text {-D- } \\
\text { glucopyranoside }\end{array}$ & $\mathrm{C}_{21} \mathrm{H}_{38} \mathrm{O}_{7}$ & Fruit & Methanol & $\begin{array}{l}\text { Liquid } \\
\text { extraction }\end{array}$ & $\begin{array}{c}\text { FAB-MS, }{ }^{1} \mathrm{H}-{ }^{13} \mathrm{C}- \\
\text { and }{ }^{13} \mathrm{C}-{ }^{1} \mathrm{H} \\
\text { COSY NMR }\end{array}$ & {$[36,38]$} \\
\hline 4 & $\begin{array}{c}(23 Z)-3 \beta- \\
\text { Acetoxycycloart-23- } \\
\text { en-25-ol }\end{array}$ & $\mathrm{C}_{32} \mathrm{H}_{52} \mathrm{O}_{3}$ & Fruit & Methanol & $\begin{array}{l}\text { Liquid } \\
\text { extraction }\end{array}$ & ESI-MS, HPLC & [36] \\
\hline 5 & $\begin{array}{c}\text { (23Z)-3 } \beta- \\
\text { Acetoxyeupha-7,23- } \\
\text { dien-25-ol }\end{array}$ & $\mathrm{C}_{32} \mathrm{H}_{52} \mathrm{O}_{3}$ & Fruit & Methanol & $\begin{array}{l}\text { Liquid } \\
\text { extraction }\end{array}$ & ESI-MS, HPLC & [36] \\
\hline 6 & $\begin{array}{c}\text { (23Z)-Cycloart-23-ene- } \\
3 \beta, 25 \text {-diol }\end{array}$ & $\mathrm{C}_{30} \mathrm{H}_{50} \mathrm{O}_{2}$ & Fruit & Methanol & $\begin{array}{l}\text { Liquid } \\
\text { extraction }\end{array}$ & ESI-MS, HPLC & [36] \\
\hline 7 & $\begin{array}{c}\text { (24R)-6 } \beta \text {-Hydroxy-24- } \\
\text { ethylcholest-4-en-3- } \\
\text { one }\end{array}$ & $\mathrm{C}_{29} \mathrm{H}_{48} \mathrm{O}_{2}$ & Leaf & $80 \%$ Ethanol & $\begin{array}{l}\text { Liquid } \\
\text { extraction }\end{array}$ & $\begin{array}{c}{ }^{1} \mathrm{H} \text {-and } \\
{ }^{13} \mathrm{C}-\mathrm{NMR}\end{array}$ & [40] \\
\hline
\end{tabular}


Table 3. Cont.

\begin{tabular}{|c|c|c|c|c|c|c|c|}
\hline No. & Compounds & $\begin{array}{c}\text { Molecular } \\
\text { Formula }\end{array}$ & Plant Parts & $\begin{array}{l}\text { Extraction } \\
\text { Solvents }\end{array}$ & $\begin{array}{l}\text { Extraction } \\
\text { Methods }\end{array}$ & $\begin{array}{l}\text { Detection } \\
\text { Methods }\end{array}$ & Ref. \\
\hline 8 & $\begin{array}{c}\text { (24RS)-3 } \beta- \\
\text { Acetoxycycloart-25- } \\
\text { en-24-ol }\end{array}$ & $\mathrm{C}_{32} \mathrm{H}_{52} \mathrm{O}_{3}$ & Fruit & Methanol & $\begin{array}{l}\text { Liquid } \\
\text { extraction }\end{array}$ & ESI-MS, HPLC & [36] \\
\hline 9 & $\begin{array}{c}\text { (24RS)-Cycloart-25-en- } \\
\text { 3ß,24-diol }\end{array}$ & $\mathrm{C}_{30} \mathrm{H}_{50} \mathrm{O}_{2}$ & Fruit & Methanol & $\begin{array}{l}\text { Liquid } \\
\text { extraction }\end{array}$ & ESI-MS, HPLC & [36] \\
\hline 10 & $\begin{array}{c}\text { (6R,7E)-4,7- } \\
\text { Megastigmadien-3,9- } \\
\text { dione }\end{array}$ & $\mathrm{C}_{11} \mathrm{H}_{18} \mathrm{O}_{2}$ & Stem & 80\% Ethanol & $\begin{array}{l}\text { Liquid } \\
\text { extraction }\end{array}$ & $\begin{array}{c}{ }^{1} \mathrm{H} \text {-and } \\
{ }^{13} \mathrm{C}-\mathrm{NMR}, \\
\text { HR-ESI-MS }\end{array}$ & [28] \\
\hline 11 & $\begin{array}{l}\text { (6R,7E,9R)-9-Hydroxy- } \\
\text { 4,7-megastigmadien-3- } \\
\text { one }\end{array}$ & $\mathrm{C}_{13} \mathrm{H}_{20} \mathrm{O}_{2}$ & Stem & $80 \%$ Ethanol & $\begin{array}{l}\text { Liquid } \\
\text { extraction }\end{array}$ & $\begin{array}{c}{ }^{1} \mathrm{H} \text {-and } \\
{ }^{13} \mathrm{C}-\mathrm{NMR}, \\
\text { HR-ESI-MS }\end{array}$ & {$[28,41]$} \\
\hline 12 & $\begin{array}{c}\text { (6S*,7E,9Z)-6,10- } \\
\text { Dihydroxy-7,9-penta- } \\
\text { dienyl-4-cyclohexen-3- } \\
\text { one }\end{array}$ & $\mathrm{C}_{14} \mathrm{H}_{20} \mathrm{O}_{3}$ & Stem & $80 \%$ Ethanol & $\begin{array}{l}\text { Liquid } \\
\text { extraction }\end{array}$ & $\begin{array}{c}{ }^{1} \mathrm{H} \text {-and } \\
{ }^{13} \mathrm{C}-\mathrm{NMR}, \\
\text { HR-ESI-MS }\end{array}$ & [28] \\
\hline 13 & $\begin{array}{c}\text { (6S,7E)-6-Hydroxy-4,7- } \\
\text { megastigmadien-3,9- } \\
\text { dione } \\
(\mathrm{E}, 4 \mathrm{R})-4-H y d r o x y-\end{array}$ & $\mathrm{C}_{13} \mathrm{H}_{18} \mathrm{O}_{3}$ & Stem & 80\% Ethanol & $\begin{array}{l}\text { Liquid } \\
\text { extraction }\end{array}$ & $\begin{array}{c}{ }^{1} \mathrm{H} \text {-and } \\
{ }^{13} \mathrm{C}-\mathrm{NMR}, \\
\text { HR-ESI-MS }\end{array}$ & {$[28,41]$} \\
\hline 14 & $\begin{array}{l}\text { 4,5,5-trimethyl-3-(3- } \\
\text { oxobut-1- } \\
\text { enyl)cyclohex-2-en- } \\
\text { one }\end{array}$ & $\mathrm{C}_{14} \mathrm{H}_{20} \mathrm{O}_{2}$ & Stem & Ethanol & $\begin{array}{l}\text { Liquid } \\
\text { extraction }\end{array}$ & $\begin{array}{c}{ }^{1} \mathrm{H} \text {-and } \\
{ }^{13} \mathrm{C}-\mathrm{NMR}\end{array}$ & {$[28,41]$} \\
\hline 15 & $\begin{array}{c}\text { 10 } \alpha, 11-H y d r o x y \\
\text { juniper-4-ene11-O- } \beta \text { - } \\
\text { D-glucopyranoside }\end{array}$ & $\mathrm{C}_{21} \mathrm{H}_{38} \mathrm{O}_{7}$ & Fruit & Methanol & $\begin{array}{l}\text { Liquid } \\
\text { extraction }\end{array}$ & $\begin{array}{c}\text { FAB-MS, }{ }^{1} \mathrm{H}-{ }^{13} \mathrm{C}- \\
\text { and }{ }^{13} \mathrm{C}-{ }^{1} \mathrm{H} \\
\text { COSY NMR }\end{array}$ & {$[36,38]$} \\
\hline 16 & $\begin{array}{c}11 \alpha \text {-Hydroxy- } \beta- \\
\text { amyrin }\end{array}$ & $\mathrm{C}_{30} \mathrm{H}_{50} \mathrm{O}_{2}$ & $\begin{array}{l}\text { Stem and } \\
\text { leaf }\end{array}$ & $\begin{array}{c}\mathrm{CHCl}_{3} / \text { methanol } \\
9: 1\end{array}$ & $\begin{array}{l}\text { Liquid } \\
\text { extraction }\end{array}$ & NMR & [27] \\
\hline 17 & $\begin{array}{c}2 \alpha, 3 \beta \text {-Dihydroxyurs- } \\
\text { 12-en-28-oic } \\
\text { acid }\end{array}$ & $\mathrm{C}_{38} \mathrm{H}_{48} \mathrm{O}_{4}$ & Leaf & Methanol & $\begin{array}{l}\text { Liquid } \\
\text { extraction }\end{array}$ & ESI-MS, HPLC & [31] \\
\hline 18 & $\begin{array}{l}\text { 3,9-Dihydroxy-5,7- } \\
\text { megastigmadien-4- } \\
\text { one }\end{array}$ & $\mathrm{C}_{13} \mathrm{H}_{19} \mathrm{O}_{3}$ & Leaf & Ethanol & $\begin{array}{l}\text { Liquid } \\
\text { extraction }\end{array}$ & $\begin{array}{c}{ }^{1} \mathrm{H} \text {-and } \\
{ }^{13} \mathrm{C}-\mathrm{NMR}\end{array}$ & [42] \\
\hline 19 & 3 -Oxo- $\alpha$-ionone & $\mathrm{C}_{13} \mathrm{H}_{18} \mathrm{O}_{2}$ & Stem & Ethanol & $\begin{array}{l}\text { Liquid } \\
\text { extraction }\end{array}$ & NMR & {$[41]$} \\
\hline 20 & 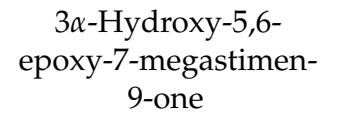 & $\mathrm{C}_{13} \mathrm{H}_{20} \mathrm{O}_{3}$ & Leaf & Ethanol & $\begin{array}{l}\text { Liquid } \\
\text { extraction }\end{array}$ & $\begin{array}{c}{ }^{1} \mathrm{H} \text {-and } \\
{ }^{13} \mathrm{C}-\mathrm{NMR}\end{array}$ & [42] \\
\hline 21 & $\begin{array}{c}3 \alpha \text {-Hydroxy-isohop- } \\
\text { 22(29)-en-24-oic } \\
\text { acid }\end{array}$ & $\mathrm{C}_{30} \mathrm{H}_{48} \mathrm{O}_{3}$ & Leaf & Methanol & $\begin{array}{l}\text { Liquid } \\
\text { extraction }\end{array}$ & $\begin{array}{l}\text { Sephadex LH-20 } \\
\text { (Methanol) } \\
\text { column } \\
\text { chromatography }\end{array}$ & [32] \\
\hline 22 & $\begin{array}{l}\text { 3ß,28-Dihydroxylup- } \\
\text { 20(29)-ene }\end{array}$ & $\mathrm{C}_{30} \mathrm{H}_{50} \mathrm{O}_{2}$ & Leaf & Methanol & $\begin{array}{l}\text { Liquid } \\
\text { extraction }\end{array}$ & ESI-MS, HPLC & [32] \\
\hline 23 & $\begin{array}{c}3 \beta, 28- \\
\text { Dihydroxyolean-12- } \\
\text { ene }\end{array}$ & $\mathrm{C}_{30} \mathrm{H}_{50} \mathrm{O}_{2}$ & Leaf & Methanol & $\begin{array}{l}\text { Liquid } \\
\text { extraction }\end{array}$ & ESI-MS, HPLC & [32] \\
\hline 24 & 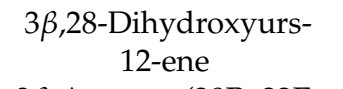 & $\mathrm{C}_{30} \mathrm{H}_{50} \mathrm{O}_{2}$ & Leaf & Methanol & $\begin{array}{l}\text { Liquid } \\
\text { extraction }\end{array}$ & ESI-MS, HPLC & [32] \\
\hline 25 & $\begin{array}{l}3 \beta \text {-Acetoxy-(20R, 22E, } \\
24 \mathrm{RS})-20,24- \\
\text { dimethoxydammarane- } \\
\text { 22-ene-25-alcohol }\end{array}$ & $\mathrm{C}_{34} \mathrm{H}_{58} \mathrm{O}_{5}$ & Fruit & Methanol & $\begin{array}{l}\text { Liquid } \\
\text { extraction }\end{array}$ & EI-MS, NMR & {$[36]$} \\
\hline
\end{tabular}


Table 3. Cont.

\begin{tabular}{|c|c|c|c|c|c|c|c|}
\hline No. & Compounds & $\begin{array}{l}\text { Molecular } \\
\text { Formula }\end{array}$ & Plant Parts & $\begin{array}{l}\text { Extraction } \\
\text { Solvents }\end{array}$ & $\begin{array}{l}\text { Extraction } \\
\text { Methods }\end{array}$ & $\begin{array}{l}\text { Detection } \\
\text { Methods }\end{array}$ & Ref. \\
\hline 26 & 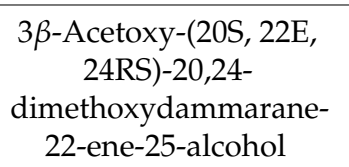 & $\mathrm{C}_{34} \mathrm{H}_{58} \mathrm{O}_{5}$ & Fruit & Methanol & $\begin{array}{l}\text { Liquid } \\
\text { extraction }\end{array}$ & EI-MS, NMR & [36] \\
\hline 27 & $\begin{array}{c}3 \beta \text {-Acetoxy- } \\
20,21,22,23,24,25,26,27- \\
\text { Octamethyldammarane- } \\
\quad 17 \beta \text {-alcohol }\end{array}$ & $\mathrm{C}_{24} \mathrm{H}_{40} \mathrm{O}_{3}$ & Fruit & Methanol & $\begin{array}{c}\text { Liquid } \\
\text { extraction }\end{array}$ & EI-MS, NMR & [36] \\
\hline 28 & $\begin{array}{c}3 \beta \text {-Acetoxy- } \\
22,23,24,25,26,27- \\
\text { hexamethyldammarane- } \\
\text { 20-one }\end{array}$ & $\mathrm{C}_{26} \mathrm{H}_{42} \mathrm{O}_{3}$ & Fruit & Methanol & $\begin{array}{l}\text { Liquid } \\
\text { extraction }\end{array}$ & $\begin{array}{c}\text { EI-MS, COSY } \\
\text { NMR }\end{array}$ & [36] \\
\hline 29 & $\begin{array}{c}3 \beta \text {-Acetoxycycloartan- } \\
24 \text {-al }\end{array}$ & $\mathrm{C}_{29} \mathrm{H}_{46} \mathrm{O}_{3}$ & Leaf & $80 \%$ Ethanol & $\begin{array}{c}\text { Liquid } \\
\text { extraction }\end{array}$ & $\begin{array}{c}{ }^{1} \mathrm{H} \text {-and } \\
{ }^{13} \mathrm{C}-\mathrm{NMR}\end{array}$ & [40] \\
\hline 30 & $\begin{array}{c}\text { 3 } \beta \text {-Hydroxy-urs-12- } \\
\text { en-28-oic } \\
\text { acid }\end{array}$ & $\mathrm{C}_{30} \mathrm{H}_{50} \mathrm{O}_{3}$ & Leaf & $70 \%$ Ethanol & $\begin{array}{l}\text { Liquid } \\
\text { extraction }\end{array}$ & $\begin{array}{c}{ }^{1} \mathrm{H} \text {-and } \\
{ }^{13} \mathrm{C}-\mathrm{NMR}\end{array}$ & {$[32,43]$} \\
\hline 31 & $\begin{array}{l}\text { 4-Megastigment-3,9- } \\
\text { dione }\end{array}$ & $\mathrm{C}_{13} \mathrm{H}_{20} \mathrm{O}_{2}$ & Stem & $80 \%$ Ethanol & $\begin{array}{l}\text { Liquid } \\
\text { extraction }\end{array}$ & $\begin{array}{c}{ }^{1} \mathrm{H} \text {-and } \\
{ }^{13} \mathrm{C}-\mathrm{NMR}\end{array}$ & {$[28,41]$} \\
\hline 32 & $\begin{array}{c}\text { 8,9-Dihydro-8,9- } \\
\text { dihydroxy- } \\
\text { megastigmatrienone }\end{array}$ & $\mathrm{C}_{13} \mathrm{H}_{20} \mathrm{O}_{3}$ & Stem & $80 \%$ Ethanol & $\begin{array}{c}\text { Liquid } \\
\text { extraction }\end{array}$ & $\begin{array}{c}{ }^{1} \mathrm{H} \text {-and } \\
{ }^{13} \mathrm{C}-\mathrm{NMR}\end{array}$ & {$[28,41]$} \\
\hline 33 & $\begin{array}{l}\text { 9,10-Dihydroxy-4,7- } \\
\text { megastigmadien-3- } \\
\text { one }\end{array}$ & $\mathrm{C}_{13} \mathrm{H}_{20} \mathrm{O}_{3}$ & Leaf & Ethanol & $\begin{array}{l}\text { Liquid } \\
\text { extraction }\end{array}$ & $\begin{array}{c}{ }^{1} \mathrm{H} \text {-and } \\
{ }^{13} \mathrm{C}-\mathrm{NMR}\end{array}$ & [42] \\
\hline 34 & Betulin & $\mathrm{C}_{30} \mathrm{H}_{50} \mathrm{O}_{2}$ & $\begin{array}{l}\text { Stem and } \\
\text { leaf, leaf }\end{array}$ & $\begin{array}{l}70 \% \text { Ethanol and } \\
\text { petroleum ether, } \\
\text { methanol }\end{array}$ & $\begin{array}{l}\text { Liquid } \\
\text { extraction }\end{array}$ & $\begin{array}{l}{ }^{1} \mathrm{H} \text {-and } \\
{ }^{13} \mathrm{C}-\mathrm{NMR}, \\
\text { ESI-MS }\end{array}$ & {$[32,43]$} \\
\hline 35 & Betulinic acid & $\mathrm{C}_{30} \mathrm{H}_{48} \mathrm{O}_{3}$ & $\begin{array}{c}\text { Above } \\
\text { ground } \\
\text { parts } \\
\text { except fruit, } \\
\text { stem, and } \\
\text { leaf }\end{array}$ & $\begin{array}{l}70 \% \text { Ethanol and } \\
\text { petroleum ether, } \\
\text { methanol }\end{array}$ & $\begin{array}{l}\text { Liquid } \\
\text { extraction }\end{array}$ & $\begin{array}{l}{ }^{1} \mathrm{H} \text {-and } \\
{ }^{13} \mathrm{C}-\mathrm{NMR}, \\
\text { ESI-MS }\end{array}$ & {$[22,29,32]$} \\
\hline 36 & cis,trans-Abscisic acid & $\mathrm{C}_{15} \mathrm{H}_{20} \mathrm{O}_{4}$ & Stem & $80 \%$ Ethanol & $\begin{array}{l}\text { Liquid } \\
\text { extraction }\end{array}$ & $\begin{array}{c}{ }^{1} \mathrm{H} \text {-and } \\
{ }^{13} \mathrm{C}-\mathrm{NMR}\end{array}$ & [28] \\
\hline 37 & Glutinol & $\mathrm{C}_{30} \mathrm{H}_{50} \mathrm{O}$ & Leaf & Methanol & $\begin{array}{l}\text { Liquid } \\
\text { extraction }\end{array}$ & ESI-MS, HPLC & [32] \\
\hline 38 & Lupenyl acetate & $\mathrm{C}_{32} \mathrm{H}_{52} \mathrm{O}_{2}$ & Leaf & Methanol & $\begin{array}{l}\text { Liquid } \\
\text { extraction }\end{array}$ & $\begin{array}{c}\text { ESI-MS, HPLC, } \\
\text { FAB-MS, }{ }^{1} \mathrm{H} \text {-and } \\
{ }^{13} \mathrm{C}-\mathrm{NMR}\end{array}$ & {$[32,36]$} \\
\hline 39 & Lupeol & $\mathrm{C}_{30} \mathrm{H}_{50} \mathrm{O}$ & $\begin{array}{c}\text { Above } \\
\text { ground } \\
\text { parts } \\
\text { except fruit, } \\
\text { stem, and } \\
\text { leaf }\end{array}$ & $\begin{array}{l}70 \% \text { Ethanol and } \\
\text { ethyl acetate, } \\
\text { methanol }\end{array}$ & $\begin{array}{c}\text { Liquid } \\
\text { extraction }\end{array}$ & $\begin{array}{l}{ }^{1} \mathrm{H} \text {-and } \\
{ }^{13} \mathrm{C}-\mathrm{NMR}, \\
\text { ESI-MS }\end{array}$ & {$[29,32,36,43]$} \\
\hline 40 & Neohopane & $\mathrm{C}_{30} \mathrm{H}_{50} \mathrm{O}_{2}$ & Leaf & Ethanol & $\begin{array}{l}\text { Liquid } \\
\text { extraction }\end{array}$ & NMR & [44] \\
\hline 41 & Phaseic acid & $\mathrm{C}_{15} \mathrm{H}_{20} \mathrm{O}_{5}$ & $\begin{array}{l}\text { Inflorescence } \\
\text { receptacle }\end{array}$ & 95\% Ethanol & $\begin{array}{c}\text { Diafiltration } \\
\text { extraction }\end{array}$ & $\begin{array}{c}\text { Silica gel, } \\
\text { Sephadex LH-20, } \\
\text { ODS, preparative } \\
\text { HPLC column } \\
\text { chromatogra- } \\
\text { phies }\end{array}$ & [35] \\
\hline
\end{tabular}


Table 3. Cont.

\begin{tabular}{|c|c|c|c|c|c|c|c|}
\hline No. & Compounds & $\begin{array}{l}\text { Molecular } \\
\text { Formula }\end{array}$ & Plant Parts & $\begin{array}{l}\text { Extraction } \\
\text { Solvents }\end{array}$ & $\begin{array}{l}\text { Extraction } \\
\text { Methods }\end{array}$ & Detection Methods & Ref. \\
\hline 42 & Pumilaside A & $\mathrm{C}_{21} \mathrm{H}_{38} \mathrm{O}_{8}$ & Fruit & Methanol & $\begin{array}{l}\text { Liquid } \\
\text { extraction }\end{array}$ & $\begin{array}{c}\text { FAB-MS, }{ }^{1} \mathrm{H} \text {-and } \\
{ }^{13} \mathrm{C}-\mathrm{NMR}\end{array}$ & [36] \\
\hline 43 & Pumilaside B & $\mathrm{C}_{21} \mathrm{H}_{36} \mathrm{O}_{7}$ & Fruit & Methanol & $\begin{array}{l}\text { Liquid } \\
\text { extraction }\end{array}$ & $\begin{array}{c}\text { FAB-MS, }{ }^{1} \mathrm{H}-{ }^{13} \mathrm{C}- \\
\text { and }{ }^{13} \mathrm{C}-{ }^{1} \mathrm{H} \text { COSY } \\
\text { NMR }\end{array}$ & [36] \\
\hline 44 & Pumilaside C & $\mathrm{C}_{21} \mathrm{H}_{36} \mathrm{O}_{7}$ & Fruit & Methanol & $\begin{array}{l}\text { Liquid } \\
\text { extraction }\end{array}$ & $\begin{array}{l}{ }^{1} \mathrm{H}-{ }^{13} \mathrm{C} \text {-and }{ }^{13}{ }^{13}-{ }^{1} \mathrm{H} \\
\text { COSY NMR, HMBC }\end{array}$ & [36] \\
\hline 45 & Rhoiptelenol & $\mathrm{C}_{30} \mathrm{H}_{50} \mathrm{O}$ & Leaf & Methanol & $\begin{array}{l}\text { Liquid } \\
\text { extraction }\end{array}$ & ESI-MS, HPLC & [32] \\
\hline 46 & Taraxerol & $\mathrm{C}_{30} \mathrm{H}_{50} \mathrm{O}$ & Leaf & Methanol & $\begin{array}{l}\text { Liquid } \\
\text { extraction }\end{array}$ & ${ }^{1} \mathrm{H}$-and ${ }^{13} \mathrm{C}-\mathrm{NMR}$ & [32] \\
\hline 47 & Taraxeryl acetate & $\mathrm{C}_{32} \mathrm{H}_{52} \mathrm{O}_{2}$ & $\begin{array}{l}\text { Stem and } \\
\text { leaf }\end{array}$ & Ethanol & $\begin{array}{l}\text { Liquid } \\
\text { extraction }\end{array}$ & $\begin{array}{l}\text { Mixed melting } \\
\text { point detection }\end{array}$ & {$[40,45]$} \\
\hline 48 & Uvaol & $\mathrm{C}_{30} \mathrm{H}_{50} \mathrm{O}_{2}$ & $\begin{array}{l}\text { Stem and } \\
\text { leaf }\end{array}$ & $\begin{array}{l}70 \% \text { Ethanol } \\
\text { and } \\
\text { petroleum } \\
\text { ether }\end{array}$ & $\begin{array}{l}\text { Liquid } \\
\text { extraction }\end{array}$ & $\begin{array}{c}{ }^{1} \mathrm{H} \text {-and }{ }^{13} \mathrm{C}-\mathrm{NMR}, \\
\text { SI-MS }\end{array}$ & [27] \\
\hline 49 & Vomifoliol & $\mathrm{C}_{13} \mathrm{H}_{20} \mathrm{O}_{3}$ & Stem & Ethanol & $\begin{array}{l}\text { Diafiltration } \\
\text { extraction }\end{array}$ & $\begin{array}{c}{ }^{1} \mathrm{H} \text {-and }{ }^{13} \mathrm{C}-\mathrm{NMR}, \\
\text { DEPT- } 135\end{array}$ & {$[28,35,41]$} \\
\hline 50 & Vomifoliol acetate & $\mathrm{C}_{15} \mathrm{H}_{22} \mathrm{O}_{4}$ & Stem & $80 \%$ Ethanol & $\begin{array}{l}\text { Liquid } \\
\text { extraction }\end{array}$ & ${ }^{1} \mathrm{H}$-and ${ }^{13} \mathrm{C}-\mathrm{NMR}$ & {$[28,41]$} \\
\hline 51 & $\alpha$-Amyrin & $\mathrm{C}_{30} \mathrm{H}_{50} \mathrm{O}$ & Leaf, fruit & Methanol & $\begin{array}{l}\text { Liquid } \\
\text { extraction }\end{array}$ & ESI-MS, HPLC & {$[31,36]$} \\
\hline 52 & $\alpha$-Amyrin acetate & $\mathrm{C}_{32} \mathrm{H}_{52} \mathrm{O}_{2}$ & Leaf, fruit & Methanol & $\begin{array}{l}\text { Liquid } \\
\text { extraction }\end{array}$ & ESI-MS, HPLC & {$[32,36]$} \\
\hline 53 & $\beta$-Amyrin & $\mathrm{C}_{30} \mathrm{H}_{50} \mathrm{O}$ & $\begin{array}{l}\text { Stem and } \\
\text { leaf, fruit }\end{array}$ & $\begin{array}{l}\text { Ethanol, } \\
\text { methanol }\end{array}$ & $\begin{array}{l}\text { Liquid } \\
\text { extraction }\end{array}$ & $\begin{array}{c}{ }^{1} \mathrm{H} \text {-and }{ }^{13} \mathrm{C}-\mathrm{NMR}, \\
\mathrm{MS}\end{array}$ & {$[27,32,36,45]$} \\
\hline 54 & $\beta$-Amyrin acetate & $\mathrm{C}_{32} \mathrm{H}_{52} \mathrm{O}_{2}$ & $\begin{array}{l}\text { Stem, leaf, } \\
\text { fruit, inflo- } \\
\text { rescence } \\
\text { receptacle }\end{array}$ & $\begin{array}{l}\text { methanol, } \\
\text { 95\% Ethanol, } \\
\text { petroleum } \\
\text { ether, ethyl } \\
\text { acetate, } \\
\text { N-butanol }\end{array}$ & $\begin{array}{l}\text { Diafiltration } \\
\text { extraction, } \\
\text { liquid } \\
\text { extraction }\end{array}$ & $\begin{array}{c}\text { Silica gel, Sephadex } \\
\text { LH-20, ODS, } \\
\text { preparative HPLC } \\
\text { column } \\
\text { Chromatographies, } \\
\text { MS }\end{array}$ & {$[22,32,35,36,46,47]$} \\
\hline
\end{tabular}

Abbreviations: ODS, octadecylsilyl; FAB-MS, fast atom bombardment mass spectrometry; COSY, correlated spectroscopy; NMR, nuclear magnetic resonance spectroscopy; HR-ESI-MS, high resolution electrospray ionization-mass spectrometry; ESI-MS, electrospray ionizationmass spectrometry; HMBC, heteronuclear multiple bond correlation; MS, mass spectrometry.

\subsection{Alcohol Compounds}

Several alcohol compounds have been isolated from the ethanol or methanol extract of Ficus pumila L. up to now, such as meso-inositol, n-octacosanol, n-nonacosanoic acid, $n$-tetracosanol, $n$-hexadecanol, and norepinephrine 3,9-dihydroxy dihydro actinidiolide [12,17,25].

\subsection{Steroids}

Seventeen steroids (Table 4) have been isolated from Ficus pumila L. These steroid compounds are widely distributed in different parts of Ficus pumila L., including leaf, steam, fruit, inflorescence, and receptacle.

\subsection{Other Compounds}

Other compounds have also been isolated from the Ficus pumila L. Kitajima et al. (1998) isolated $\alpha$-tocopherol and VE-FPL ( $3 \alpha$-acetyl-2,3,5-trimethyl-7 $\alpha$-hydroxy-5- $(4,8,12-$ trimethyl-tridecanyl)-1,3 $\alpha, 5,6,7,7 \alpha$-hexahydro-4-oxainden-1-one) from the leaves of Ficus pumila L. [32]. In addition, $\beta$-D-glucopyranoside and (E)-2-methyl-2-butenyl were isolated from the fruits of Ficus pumila L. [36]. Fan et al. (2005) isolated ethyl- $\beta$-D-glucopyranoside from the fruit-removing part of Ficus pumila L. by using 75\% ethanol [29]. Wei et al. (2014) isolated 1-methyl-1, 2, 3, 4-tetrahydro- $\beta$-carboline-3-carboxylic acid, an alkaloid, 
from dried inflorescence of Ficus pumila L. by using 95\% ethanol [35]. Trinh et al. (2018) isolated a new benzofuran derivative, pumiloside, from the ethanol extract of Ficus pumila L. [31]. Moreover, Xiao et al. (2015) isolated a new compound from Ficus pumila L., named 5-aldehyde-4'-hydroxy-2,2'-dimethoxybiphenyl [28]. Cai et al. (2017) isolated trans ethyl $p$-hydroxycinnamate, pubinernoid A, and oxindole [40]. Bai et al. (2019) isolated blumenol A, (6R, 9R)-3-oxo-ationol-onolglucopyranoside, roseoside (rosmarinin), and (E)-4-[3'-( $\beta$-Dglucopyranosyloxy)butylidene]-3,5,5-trimethyl-2-cyclohexen-l-one from Ficus pumila L. [42].

Table 4. Steroid compounds found in Ficus pumila L.

\begin{tabular}{|c|c|c|c|c|c|c|c|}
\hline No. & Compounds & $\begin{array}{l}\text { Molecular } \\
\text { Formula }\end{array}$ & Plant Parts & $\begin{array}{l}\text { Extraction } \\
\text { Solvents }\end{array}$ & $\begin{array}{l}\text { Extraction } \\
\text { Methods }\end{array}$ & $\begin{array}{l}\text { Detection } \\
\text { Methods }\end{array}$ & Ref. \\
\hline 1 & $\begin{array}{c}\text { (24S)-Stigmast-5-ene- } \\
\text { 3ß,24-diol }\end{array}$ & $\mathrm{C}_{29} \mathrm{H}_{50} \mathrm{O}_{2}$ & Fruit & Methanol & $\begin{array}{l}\text { Liquid } \\
\text { extraction }\end{array}$ & NMR & [46] \\
\hline 2 & $\begin{array}{l}\text { (24S)-24- } \\
\text { Hydroxystigmast-4-en-3- } \\
\text { one }\end{array}$ & $\mathrm{C}_{29} \mathrm{H}_{48} \mathrm{O}_{2}$ & Fruit & Methanol & $\begin{array}{l}\text { Liquid } \\
\text { extraction }\end{array}$ & NMR & [46] \\
\hline 3 & $\begin{array}{l}\text { 3 } \beta \text {-Hydroxysitost-5-en-7- } \\
\text { one }\end{array}$ & $\mathrm{C}_{29} \mathrm{H}_{48} \mathrm{O}_{2}$ & Stem & $80 \%$ Ethanol & $\begin{array}{c}\text { Liquid } \\
\text { extraction }\end{array}$ & HPLC & [28] \\
\hline 4 & $5 \alpha$-Stigmastan-2,6-dione & $\mathrm{C}_{29} \mathrm{H}_{48} \mathrm{O}_{2}$ & $\begin{array}{l}\text { Leaf and } \\
\text { stem }\end{array}$ & $\begin{array}{l}70 \% \text { Ethanol } \\
\text { and } \\
\text { petroleum } \\
\text { ether }\end{array}$ & $\begin{array}{l}\text { Liquid } \\
\text { extraction }\end{array}$ & ESI-MS & [43] \\
\hline 5 & $\begin{array}{l}6 \alpha \text {-Hydroxystigmast-4- } \\
\text { en-3-one }\end{array}$ & $\mathrm{C}_{29} \mathrm{H}_{48} \mathrm{O}_{2}$ & Stem & $80 \%$ Ethanol & $\begin{array}{l}\text { Liquid } \\
\text { extraction }\end{array}$ & HPLC & [28] \\
\hline 6 & $\begin{array}{l}\text { 6ß-Hydroxystigmast-4- } \\
\text { en-3-one }\end{array}$ & $\mathrm{C}_{29} \mathrm{H}_{48} \mathrm{O}_{2}$ & Stem & $80 \%$ Ethanol & $\begin{array}{c}\text { Liquid } \\
\text { extraction }\end{array}$ & HPLC & [28] \\
\hline 7 & 7-Keto- $\beta$-sitosterol & $\mathrm{C}_{29} \mathrm{H}_{48} \mathrm{O}_{2}$ & Leaf & $80 \%$ Ethanol & $\begin{array}{l}\text { Liquid } \\
\text { extraction }\end{array}$ & $\begin{array}{c}{ }^{1} \mathrm{H} \text {-and } \\
{ }^{13} \mathrm{C}-\mathrm{NMR}\end{array}$ & [40] \\
\hline 8 & Campesterol & $\mathrm{C}_{28} \mathrm{H}_{48} \mathrm{O}$ & Fruit & Methanol & $\begin{array}{l}\text { Liquid } \\
\text { extraction }\end{array}$ & NMR & [46] \\
\hline 9 & Cholesterol & $\mathrm{C}_{27} \mathrm{H}_{46} \mathrm{O}$ & Fruit & Methanol & $\begin{array}{c}\text { Liquid } \\
\text { extraction }\end{array}$ & NMR & [46] \\
\hline 10 & Daucosterol & $\mathrm{C}_{35} \mathrm{H}_{60} \mathrm{O}_{6}$ & $\begin{array}{l}\text { Leaf and } \\
\text { stem, inflo- } \\
\text { rescence } \\
\text { receptacle, } \\
\text { and above- } \\
\text { ground } \\
\text { parts } \\
\text { except fruit }\end{array}$ & $\begin{array}{l}70 \% \text { Ethanol } \\
\text { and ethyl } \\
\text { acetate, } \\
\text { methanol }\end{array}$ & $\begin{array}{l}\text { Diafiltration } \\
\text { extraction }\end{array}$ & $\begin{array}{c}\text { Silica gel, } \\
\text { Sephadex } \\
\text { LH-20, ODS, } \\
\text { and } \\
\text { preparative } \\
\text { HPLC column } \\
\text { chromatogra- } \\
\text { phies; } \\
\text { TLC }\end{array}$ & {$[29,32,35,43]$} \\
\hline 11 & $\begin{array}{l}\text { Dihydrodehydrodiconiferyl } \\
\text { alcohol }\end{array}$ & $\mathrm{C}_{20} \mathrm{H}_{24} \mathrm{O}_{6}$ & Leaf & $80 \%$ Ethanol & $\begin{array}{l}\text { Liquid } \\
\text { extraction }\end{array}$ & $\begin{array}{c}{ }^{1} \mathrm{H} \text {-and } \\
{ }^{13} \mathrm{C}-\mathrm{NMR}\end{array}$ & [40] \\
\hline 12 & Stigmast-4-en-3-one & $\mathrm{C}_{29} \mathrm{H}_{48} \mathrm{O}$ & Fruit & Methanol & $\begin{array}{c}\text { Liquid } \\
\text { extraction }\end{array}$ & NMR & {$[46]$} \\
\hline 13 & $\begin{array}{c}\text { Stigmast-5,24(28)-dien-3- } \\
\text { ol }\end{array}$ & $\mathrm{C}_{29} \mathrm{H}_{48} \mathrm{O}$ & $\begin{array}{l}\text { Leaf and } \\
\text { stem }\end{array}$ & $\begin{array}{l}70 \% \text { Ethanol } \\
\text { and } \\
\text { petroleum } \\
\text { ether }\end{array}$ & $\begin{array}{l}\text { Liquid } \\
\text { extraction }\end{array}$ & $\begin{array}{l}{ }^{1} \mathrm{H} \text {-and } \\
{ }^{13} \mathrm{C}-\mathrm{NMR}, \\
\text { ESI-MS }\end{array}$ & [43] \\
\hline
\end{tabular}


Table 4. Cont

\begin{tabular}{|c|c|c|c|c|c|c|c|}
\hline No. & Compounds & $\begin{array}{l}\text { Molecular } \\
\text { Formula }\end{array}$ & Plant Parts & $\begin{array}{l}\text { Extraction } \\
\text { Solvents }\end{array}$ & $\begin{array}{l}\text { Extraction } \\
\text { Methods }\end{array}$ & $\begin{array}{l}\text { Detection } \\
\text { Methods }\end{array}$ & Ref. \\
\hline 14 & Stigmasterol & $\mathrm{C}_{29} \mathrm{H}_{48} \mathrm{O}$ & $\begin{array}{l}\text { Leaf and } \\
\text { stem }\end{array}$ & $\begin{array}{l}70 \% \text { Ethanol } \\
\text { and ethyl } \\
\text { acetate }\end{array}$ & $\begin{array}{c}\text { Liquid } \\
\text { extraction }\end{array}$ & $\begin{array}{c}{ }^{1} \mathrm{H} \text {-and } \\
{ }^{13} \mathrm{C}-\mathrm{NMR}, \\
\text { ESI-MS }\end{array}$ & [43] \\
\hline 15 & $\beta$-Daucosterol & $\mathrm{C}_{35} \mathrm{H}_{60} \mathrm{O}_{6}$ & $\begin{array}{l}\text { Inflorescence } \\
\text { receptacle }\end{array}$ & Ethanol & $\begin{array}{l}\text { Diafiltration } \\
\text { extraction }\end{array}$ & $\begin{array}{c}\text { Silica gel, } \\
\text { Sephadex } \\
\text { LH-20, ODS, } \\
\text { and } \\
\text { preparative } \\
\text { HPLC column } \\
\text { chromatogra- } \\
\text { phies }\end{array}$ & {$[35]$} \\
\hline 16 & $\beta$-Sitosterol & $\mathrm{C}_{29} \mathrm{H}_{50} \mathrm{O}$ & $\begin{array}{l}\text { Leaf, stem, } \\
\text { fruit, inflo- } \\
\text { rescence } \\
\text { receptacle }\end{array}$ & $\begin{array}{c}70 \% \text { Ethanol } \\
\text { and } \\
\text { petroleum } \\
\text { ether, } \\
\text { methanol, } \\
\mathrm{CHCl}_{3} / \text { methano } \\
9: 1\end{array}$ & $\begin{array}{l}\text { Liquid } \\
\text { extraction } \\
\text { l }\end{array}$ & $\begin{array}{l}\text { Mixed melting } \\
\text { point detection, } \\
\text { Silica gel } \\
\text { column chro- } \\
\text { matography, } \\
\text { Sephadex } \\
\text { LH-20 column } \\
\text { chromatogra- } \\
\text { phy, TLC, } \\
\text { ESI-MS }\end{array}$ & {$[27-29,32,43,45,46]$} \\
\hline 17 & $\begin{array}{l}\beta \text {-Sitosterol-3-O- } \beta \text {-D- } \\
\text { glucopyranoside- } 6 \text { - } \\
\text { pentadecanoate }\end{array}$ & $\mathrm{C}_{50} \mathrm{H}_{90} \mathrm{O}_{7}$ & $\begin{array}{l}\text { Aboveground } \\
\text { parts } \\
\text { except fruit }\end{array}$ & $\begin{array}{c}75 \% \\
\text { Industrial } \\
\text { ethanol }\end{array}$ & $\begin{array}{c}\text { Liquid } \\
\text { extraction }\end{array}$ & $\begin{array}{l}{ }^{1} \text { H-and } \\
{ }^{13} \text { C-NMR, } \\
\text { EI-MS }\end{array}$ & [29] \\
\hline
\end{tabular}

Abbreviations: NMR, nuclear magnetic resonance spectroscopy; HPLC, high performance liquid chromatography; ESI-MS, electrospray ionization; ODS, octadecylsilyl; TLC, thin-layer chromatography; SI-MS, secondary ion mass spectroscopy; ESI-MS, electron impact-mass spectrometry.

\section{Therapeutic Activities of Ficus pumila L.}

Quite a few plant-derived bioactive compounds and extracts have received much attention because of their potential health benefits [48-55]. Some Ficus plants have been used in traditional medicine for a long time, and their pharmacological activities have been summarized in recent reviews [12-17]. Accumulating studies have demonstrated that Ficus pumila L.-derived bioactive compounds and extracts possess multiple therapeutic activities, which are discussed as follows.

\subsection{Antioxidant Effects}

Several studies have reported the antioxidant effects of bioactive compounds or extracts from the root, stem, leaf, and fruit of Ficus pumila L. Flavonoid glycosides such as rutin, kaempferol 3-rutinoside, kaempferol 3-robinobioside, and apigenin 6-neohesperidose isolated from the leaves of Ficus pumila L. showed strong antioxidant activities in superoxide radical inhibition assay and 1,1-diphenyl-2-picrilhydrazyl (DPPH) radical scavenging assay [30]. Moreover, the total phenolic content may contribute to the antioxidant ability of Ficus pumila L. Wang et al. (2009) evaluated the antioxidant ability of various concentrations of ethanol extracts from the fruit of Ficus pumila L. by multiple in vitro assays including DPPH assay, ferric reducing antioxidant power (FRAP) assay, trolox equivalent antioxidant capacity (TEAC) assay, and reducing power assay, and the results showed that the $80 \%$ ethanol extract had the highest total phenolic content and exhibited the strongest antioxidant activities [56]. Tang et al. (2012) investigated the antioxidant activities of different solvents and water extracts from Ficus pumila L. stem and leaves and found that the total phenolic content was correlated with the antioxidant capacity [57]. In addition, Noronha, et al. (2014) determined the antioxidant activities of hydroethanolic extracts from dried 
and fresh root, stem, leaf, and fruit of Ficus pumila L., and found fresh stem exhibited the strongest antioxidant capacity by DPPH assay [18].

\subsection{Anti-Inflammatory Effect}

It has been reported that Ficus pumila L. exhibits quite evident anti-inflammatory properties in well-recognized animal inflammatory models of xylene-induced ear swelling, carrageenan-induced toe swelling, and glacial acetic acid-induced celiac capillary permeability. The extracts from different parts of Ficus pumila L. could stimulate the celiac capillary permeability and inhibit ear and toe swelling in bilateral adrenalectomy mice compare to the blank controls, which indicated a hypothalamus-pituitary-adrenal axis-independent anti-inflammatory effect of Ficus pumila L. [58].

The systematic solvent method was applied to separate the chemical composition of Ficus pumila L. by Mao et al. (2011); three fractions were obtained, namely water extract, ethyl acetate extract, and butanol extract, which were then used to evaluate the anti-inflammatory activities [59]. The results showed that the water and ethyl acetate extracts were the effective parts that significantly inhibited the xylene-induced auricular inflammation in rats and carrageenan-induced footpad inflammation in mice, while they increased the celiac capillary permeability of mice as well [59]. In another study, they investigated the anti-inflammatory effects of water and different solvents extractions including ethanol, ethyl acetate, petroleum ether, and butanol of Ficus pumila L. by using the ear swelling mouse model and acetic acid capillary permeability assay, and the results showed that all the groups exhibited active anti-inflammatory effects except for the petroleum ether extraction [60].

Flavone and triterpene, such as rutin, luteolin, and apigenin, are the main bioactive components of Ficus pumila L. that contribute to its anti-inflammatory effect [19]. The contents of rutin, apigenin, and luteolin in the methanol extract of Ficus pumila L. are $24.41 \mathrm{mg} / \mathrm{g}, 14.11 \mathrm{mg} / \mathrm{g}$, and $2.72 \mathrm{mg} / \mathrm{g}$, respectively [19]. The Ficus pumila L. methanol extraction had a similar inhibitory effect as indomethacin on n-carrageenan-induced paw edema in mice, and the anti-inflammatory mechanism may be associated with the decreased levels of inflammatory factors such as interleukin- $1 \beta$ (IL-1 $\beta$ ), tumor necrosis factor $\alpha$ (TNF- $\alpha)$, and cyclooxygenase-2 (COX-2), and increased hepatic antioxidant enzyme activities, such as superoxide dismutase (SOD), glutathione peroxidase (GPx), and glutathione reductase (GRd), which causes a reduction of nitric oxide (NO) and malonaldehyde (MDA) levels in the edema paw [19]. Additionally, an analgesic effect of the methanol extract of Ficus pumila L. was also demonstrated by recording the writhing response and licking time in mice models of acetic acid writhing and formalin pain, respectively [19].

Recently, an arabinogalactan isolated from Ficus pumila L. fruit hulls was found to have immunomodulatory activities [61]. It could promote the nitric oxide generation, phagocytic activity, and cytokine secretion, such as TNF- $\alpha$, IL-1 $\beta$, and IL-6, in RAW 264.7 cells [61].

\subsection{Antibacterial Effect}

Ficus pumila L. has natural antibacterial effects on both Gram-positive and Gramnegative bacteria, especially Bacillus and Staphylococcus. Studies have shown that sesquiterpenes, triterpenes, and flavonoids are the main bioactive components that contributed to the antibacterial effects of Ficus pumila L. The ethyl acetate extract of the stem and leaf of Ficus pumila L. showed a 95.83\% inhibition rate against Staphylococcus aureus [62]. Compounds isolated from an ethyl acetate extract of Ficus pumila L. exhibited great antibacterial properties; 8,9-dihydro-8,9-dihydroxy-megastigmatrienone and (E,4R)-4-hydroxy-4,5,5-trimethyl3-(3-oxobut-enyl)cyclohex-2-enone showed a strong inhibitory activity against Escherichia coli with a MIC of $1.25 \mu \mathrm{g} / \mathrm{mL}$, (E,4R)-4-hydroxy-4,5,5-trimethyl-3-(3-oxobut-enyl)cyclohex2-enone had a MIC of $2.5 \mu \mathrm{g} / \mathrm{mL}$ for Staphylococcus albus, while 8,9-dihydro-8,9-dihydroxymegastigmatrienone had a weak inhibitory activity with the MIC of $5.0 \mu \mathrm{g} / \mathrm{mL}$ against Staphylococcus albus, Bacillus cereus, and Bacillus subtilis [41]. In addition, the ethanol extract of Ficus pumila L.'s stems and leaves had antibacterial effects on Staphylococcus aureus, 
Escherichia coli, and Candida albicans, among which the best antibacterial effect was on Staphylococcus aureus, and the inhibition rate could reach 100\% [62]. Moreover, the fish pathogen Aeromonas hydrophila isolated from infected rainbow trout demonstrated the highest susceptibility, with 10-12 mm inhibition zones, to the ethanolic extracts from leaves of Ficus pumila L. among the ethanolic leaves extracts from various species of Ficus by in vitro antimicrobial susceptibility testing [20].

A dried leaf extract of Ficus pumila L., rich in flavonoids, had a quercetin content of $15.30 \mathrm{mg} / \mathrm{g}$, which showed a certain degree of inhibition on Bacillus subtilis, Bacillus cereus, Enterococcus faecalis, Micrococcus luteus, Proteus mirabili, and Staphylococcus aureus [18]. It has been found that quercetin plays a role in antibacterial and antiviral infection by regulating the cysteinyl aspartate specific protease-3 (caspase-3) protein-mediated apoptosis [63], which may contributed to the antibacterial effect of Ficus pumila L., although the specific compounds in Ficus pumila L. extracts still need to be further studied.

\subsection{Antitumor Effect}

It has been reported that the crude extract of Ficus pumila L. showed cytotoxicity in the human leukemia cancer cell line (MT-4) with an IC50 value of $131 \mu \mathrm{g} / \mathrm{mL}$, while higher cytotoxic activities were found in the chloroform and butanol fractions with IC50 values of $23 \mu \mathrm{g} / \mathrm{mL}$ and $26 \mu \mathrm{g} / \mathrm{mL}$, respectively [64]. The methyl thiazolyl tetrazolium (MTT) method was used to evaluate the cytotoxic activity of the compounds extracted from the $85 \%$ ethanol aqueous solution of Ficus pumila L. against Hela, MCF-7, and A549 cell lines [42]. The results showed that the compounds dehydrovomifoliol and (E)-3-oxoretro- $\alpha$-ionol performed medium cytotoxic activity, weakened cytotoxicity against Hela, MCF-7, and A549 cells with IC50 values of 32.32 and $33.70 \mu \mathrm{g} / \mathrm{mL}$, respectively, and the effect of these two compounds in Ficus pumila L. against Hela, MCF-7, and A549 target cells activity was greater than that of other compounds, indicating that the carbonyl carbon at C-9 may be essential for the cytotoxic activity of ionone sesquiterpenes [42]. Flavonoids, sesquiterpenes, and other compounds were isolated from the stems of Ficus pumila L., and two of the flavonoids, apigenin and alpinum isoflavone, were found to inhibit breast cancer cells (MCF-7) with IC50 values of $32.5 \mu \mathrm{g} / \mathrm{mL}$ and $37.3 \mu \mathrm{g} / \mathrm{mL}$, respectively [28].

\subsection{Hypoglycemic Effect}

Both in vitro and in vivo studies supported the hypoglycemic activities of the extracts of Ficus pumila L., and the hypoglycemic effects may due to the contents of flavonoids and polysaccharides.

An in vitro study revealed that flavonoids might be the main components that contributed to the hypoglycemic effect of Ficus pumila L., as the total flavonoids content was correlated with the $\alpha$-glucosidase inhibitory activity of the extracts from rhizome of Ficus pumila L. [33]. The rhizome extraction contained the highest flavonoid content and displayed the strongest inhibitory activity toward $\alpha$-glucosidase with an IC50 up to $0.018 \mathrm{~g} / \mathrm{L}$, which is better than the effect of acarbose, a clinical hypoglycemic drug, with an IC50 of $1.075 \mathrm{~g} / \mathrm{L}$ [33]. In addition, the rhizome extracts of Ficus pumila L. also showed a high inhibitory effect on acetylcholinesterase with an IC50 up to $0.133 \mathrm{~g} / \mathrm{L}$, close to that of tacrine [33].

A pectic polysaccharide with a branched-chain of hexenuronic acid methyl ester linking to a linear $(1,4)$-alpha-D-galacturonic acid was obtained from the fruits of Ficus pumila L., and the in vivo study demonstrated that it had a strong hypoglycemic effect in the diabetic model of C57BL/KsJ db/db mice [22]. Results from the study showed that the Ficus pumila L. pectic polysaccharide significantly ameliorated hyperglycemia and improved hepatic glycogen metabolism by activating the adenosine monophosphate-activated protein kinase (AMPK) / glycogen synthase kinase-3 $\beta$ (GSK3 $\beta$ ) /glycogen synthase (GS) and insulin receptor substrate-1 (IRS-1)/phosphatidylinositol 3-kinase (PI3K)/Akt/GSK3 $\beta /$ GS pathways and regulating the expressions of glucokinase, glucose-6-phosphatase, and phosphoenolpyruvate carboxykinase [22]. 
Studies have revealed that Ficus pumila L. and its bioactive compounds can ameliorate hyperglycemia. Several in vivo studies have demonstrated the antidiabetic activity of flavonoids or extracts from other Ficus plants in diabetic animals [65-67]. Therefore, Ficus pumila L. might be a good source of natural ingredients for the prevention and management of diabetes.

\subsection{Gastrointestinal Protection}

The seed surface of Ficus pumila L. is rich in pectin, the water extract of which has the property of spontaneous gel-formation at room temperature [68]. Accumulating data have revealed the protective effects of Ficus pumila L. pectin on gastrointestinal health. The bioactive compounds of Ficus pumila L., especially the pectin, can ameliorate gastrointestinal damages and improve gastrointestinal environments. Capsaicin-induced intestinal discomfort reactions, such as the alteration of intestinal microflora, the reduction of short-chain fatty acids, and the increase of $\mathrm{pH}$ and free ammonia levels, were found to be ameliorated by treatment with pectin from Ficus pumila L. seeds through both in vitro studies in an intestinal fermentation environment [69] and in vivo studies in capsaicin-induced ovariectomized rats [70]. Further studies demonstrated that Ficus pumila L. seeds pectin can decrease cecum free ammonia, and increase cecum short-chain fatty acids, cecum weight, cecum contents, fecal bulk, and the ratio of beneficial bacteria to harmful bacteria, as well as the amount of Anaerobes, Bifidobacterium, and Lactobacillus in ovariectomized rats [71]. Moreover, similar protective effects of Ficus pumila L. seed pectin were also found in high-fat diet-fed ovariectomized rats, although there was no effect on high-fat diet-induced hyperlipidemia [72]. Recently, a homogalacturonan-type pectic polysaccharide isolated from the fruits of Ficus pumila L. was found to possess beneficial effects on high-fat diet-induced obesity in mice [23]. The results showed that the Ficus pumila L. pectic polysaccharide can reduce body weight and ameliorate the high levels of serum total cholesterol (TC) and low-density lipoprotein cholesterol (LDL-C) by modulating gut microbiota and metabolites [23].

\subsection{Hepatorenal Protection}

The extracts of Ficus plants, including Ficus pumila L., have been shown to possess significant protective effects on the liver and kidney [7,73-76]. As mentioned above, Ficus pumila $\mathrm{L}$. is rich in various natural antioxidants, and the in vivo antioxidant properties have been reported from the methanol extract of Ficus pumila L. by increasing the antioxidant enzyme activities, including SOD, GPx, and GRd, in mice liver [19]. The hepatoprotective effect of Ficus pumila L. was then evaluated in the liver damaged model of SpragueDawley rats induced by carbon tetrachloride [24]. The results showed that the biochemical indicators of liver damage, such as increased levels of cholesterol and triglyceride, and elevated concentrations of total and indirect bilirubin, were obviously restored by the administration of 50\% hydroethanolic leaf extract of Ficus pumila L. [24]. Moreover, the nephroprotective effect of Ficus pumila L. was demonstrated in a kidney damage model of female Wistar albino rats induced by gentamicin [77]. The data showed that hydroethanolic leaf extract of Ficus pumila L. was able to reduce gentamicin nephrotoxicity, which is characterized by changes of biochemical and hematological markers, such as increased levels of serum creatinine, potassium, sodium, urea, and white blood cells, and decreased levels of hemoglobin, mean cell hemoglobin, mean cell volume, and red blood cell [77]. Furthermore, the aqueous extracts of Ficus pumila L. fruits were revealed to have the effects on invigorating kidney and strengthened yang, and the extract from syconium fruits of Ficus pumila L. showed a better effect than that from the receptacle of inflorescence extract of Ficus pumila L. [78]. Thus, Ficus pumila L. has the potential to be exploited as a functional food or therapeutic agent against liver and kidney diseases. 


\subsection{Cardiovascular Protection}

A clinical test has been conducted recently to verify the health beneficial effects of the leaf extracts of Ficus pumila L. on outpatients with hypertension and dyslipidemia, and the results showed that the Ficus pumila L. leaf extracts significantly reduced the body mass index, lowered both systolic and diastolic blood pressure, and improved lipid abnormalities, which indicated the cardiovascular protective effects of Ficus pumila L. [25]. Moreover, it was found that four kinds of fatty acid, namely palmatic acid (6.68\%), oleic acid $(12.67 \%)$, linoleic acid $(14.42 \%)$, and $\alpha$-linolenic acid $(66.23 \%)$, are the main constituents of Ficus pumila L. seed oil by using supercritical carbon dioxide extraction method to extract oil from Ficus pumila L. seeds, of which the content of $\alpha$-linolenic acid was 10 times than that of ordinary soybean oil [47]. Linoleic acid and $\alpha$-linolenic acid are the most important essential fatty acids of the human body, which can be combined with cholesterol to prevent and treat cardiovascular diseases [47]. The supplementation of $\alpha$-linolenic acid was able to improve cardiac function and have a protective effect on ischemic heart failure in a rat model of myocardial infarction by inhibiting the expression of NLR family, pyrin domain containing 3 (NLRP3), and the activity of caspase-1, and by reducing the levels of TNF-a, IL$1 \beta$, and IL-6 [79]. Moreover, it has also been found that $\alpha$-linolenic acid plays a key role in reducing blood sugar and blood lipids in patients with mild to moderate hypertension [80].

\subsection{Other Therapeutic Activities}

Ficus pumila L. extracts were found to display a significant anti-hyperprolactinemic effect in metoclopramide dihydrochloride-induced hyperprolactinemic rats [81]. Moreover, it has been reported that the pectin from the seeds of Ficus pumila L. could increase the cecum area and the contents of short-chain fatty acids in the cecum and decrease the $\mathrm{pH}$ of the cecum contents, but it had a negative effect on mineral absorption in ovariectomized rats [82].

\section{Study on the Development and Utilization of Ficus pumila L.}

\subsection{Industrial Applications}

The quilt, seed, and achene of Ficus pumila L. are rich in nutrients. Wu et al. (1999) showed that the pectin content is up to $32.70 \%$ and the crude fat content is only $2.67 \%$ in Ficus pumila L. flowers [83]. The protein content is $39.88 \%$ in Ficus pumila L. pollen, much higher than that of ordinary plant pollen, and the amino acids content is up to $39.41 \%$, of which $14.56 \%$ is the essential amino acids content [83]. Ficus pumila L. also contains mineral elements, vitamins, and flavonoids that are beneficial to human health. Yao and Pei (2008) employed supercritical carbon dioxide fluid extraction technology to extract seed oil from Ficus pumila L., and the maximum extraction rate could reach $20.93 \%$ [47]. In addition, the content of unsaturated fatty acids in Ficus pumila L. seed oil is as high as $93.32 \%$, which contains a variety of beneficial fatty acids, and the flavor and quality are extremely high [47]. Therefore, the different parts of Ficus pumila L. have been widely used for making food gels, jelly, healthy beverages, or other functional foods [84-86]. Most importantly, it has been reported that Ficus pumila L. was non-toxic to mice with a dosage of $231.6 \mathrm{~g} / \mathrm{kg}$ [87].

In addition to being widely used in the food industry, the high content of pectin in Ficus pumila L. is also a great resource to develop thickeners, emulsifiers, and stabilizers. Moreover, the peel milk of Ficus pumila L. can be utilized to make rubber, while the vines can be applied to produce paper. Furthermore, Ficus pumila L. vines possess good properties of toughness, strength, and wear resistance and can also be used as a raw material for the production of various types of woven handicrafts.

\subsection{Ecological City Construction}

Ficus pumila L., a vine plant with strong ecological restoration ability, possesses multiple benefits for the urban environment, such as improving urban hydrology, reducing urban air pollution, saving energy, providing habitat for urban wildlife, and beautifying the 
urban landscape. Ficus pumila L. was selected as one of the plant species to construct green roofs to study whether the water quality of the green roofs would be affected by substrates and plant species, and it was found that Ficus pumila L. resulted in the lowest concentrations of total phosphorous in both substrate units, suggesting that Ficus pumila L. may have the potential to reduce urban water and land pollution of phosphorus [88]. Tian et al. (2014) found that Ficus pumila L. has certain effects on water and soil conservation as well as nutrient retention [89]. Li et al. (2008) evaluated the ecological benefits of Ficus pumila L. and 11 other plant species with high potential for vertical greening [90]. The results showed that Ficus pumila L. displays an admirable performance in ecological benefits, ranking second next to Thunbergia laurifolia, and it could release oxygen by $32.52 \mathrm{~g} \cdot \mathrm{m}^{-2}$.day ${ }^{-1}$, absorb carbon dioxide by $44.73 \mathrm{~g} . \mathrm{m}^{-2}$. day ${ }^{-1}$, reduce air temperature by $1.01^{\circ} \mathrm{C} / 1000 \mathrm{~m}^{3}$, and increase air humidity by $1.13 \%$ [90]. Moreover, by using the ion beam irradiation method, Takahashi et al. (2012) produced novel mutants of Ficus pumila L. with an enhanced capacity to take up and assimilate atmospheric nitrogen dioxide compared to the wild-type controls, indicating that these mutants of Ficus pumila L. have a protective effect on mitigating urban air pollution, especially the atmospheric nitrogen dioxide [91]. In addition, Corlett (2006) demonstrated the importance of the urban fig flora, including Ficus pumila L. and other native or exotic Ficus species, to the urban wildlife in Hong Kong [92]. Ficus pumila L. also showed wide ecological adaptability [93], great vertical greening effect [94], and high tolerance to soil manganese contamination [95]. Furthermore, Ficus pumila L. has great ornamental value and is very easy to care for and maintain [1,96,97]. Therefore, Ficus pumila L. is considered to be used as a three-dimensional greening plant in the reinforced concrete city or a heavy metal contaminated land restoration plant through artificial breeding [98]. Moreover, tissue culture and other rapidly propagation techniques of Ficus pumila L. have been reported $[99,100]$. Thus, in the future, Ficus pumila L. will have broad application prospects, not only to be used as a beautifying plant for decorating home balconies and urban vertical greening of buildings, gardens, roads, and parks, but also applied as an ecological remediation unit for the treatment of soil contamination, water eutrophication, and air pollution, as well as soil-water conservation.

\section{Conclusions}

Ficus pumila L. is a kind of medicinal and practical plant. Ficus pumila L. is rich in nutrients and minerals. The pectin and various fatty acids have been applied in the food industry. It also contains many bioactive components, such as phenolic acids, flavonoids, polysaccharides, terpenoids, alcohols, and steroids. Ficus pumila L. extracts and their bioactive compounds exhibit multiple therapeutic activities, including antioxidant, antiinflammatory, antibacterial, antitumor, hypoglycemic, and cardiovascular protective activities. Generally, Ficus pumila L. is non-toxic. Therefore, Ficus pumila L. and the contained bioactive components are promising as functional foods for the prevention and treatment of different kinds of diseases. In recent years, with the optimization of extraction techniques and methods, a variety of new compounds has been extracted from Ficus pumila L. Therefore, more therapeutic activities of these bioactive compounds from Ficus pumila L. should be evaluated, and more studies should be conducted to demonstrate the signaling pathways and mechanisms of action in the future. Moreover, Ficus pumila L. has great potential in ecological restoration and vertical greening, and the values of Ficus pumila L. in ecological restoration and greening should also attract special attention.

Author Contributions: Conceptualization, Z.-Y.Q. and R.-Y.G.; data curation, J.-Y.Z.; writingoriginal draft preparation, J.-Y.Z.; writing-review and editing, F.-J.L., W.-L.Z., and R.-Y.G.; supervision, Z.-Y.Q. and R.-Y.G.; project administration, Z.-Y.Q. and R.-Y.G.; funding acquisition, Z.-Y.Q. and R.-Y.G. All authors have read and agreed to the published version of the manuscript.

Funding: This research was funded by the Local Financial Funds of National Agricultural Science and Technology Center, Chengdu (No. NASC2020AR09), “Rongpiao Plan” Innovative Talent Project, and the Central Public-Interest Scientific Institution Basal Research Fund of Institute of Urban Agriculture, Chinese Academy of Agricultural Sciences (No. Y2020XK05; S2020001). 
Institutional Review Board Statement: Not applicable.

Informed Consent Statement: Not applicable.

Data Availability Statement: Data sharing not applicable.

Conflicts of Interest: The authors declare no conflict of interest.

\section{References}

1. Bao, Q. Ornamental value and application study of woody climbing plants in northwestern Fujian. J. Zhejiang For. Coll. 2000, 17, 225-228.

2. Deepa, P.; Sowndhararajan, K.; Kim, S.; Park, S.J. A role of Ficus species in the management of diabetes mellitus: A review. J. Ethnopharmacol. 2018, 215, 210-232. [CrossRef]

3. Salehi, B.; Mishra, A.P.; Nigam, M.; Karazhan, N.; Shukla, I.; Kieltyka-Dadasiewicz, A.; Sawicka, B.; Glowacka, A.; Abu-Darwish, M.S.; Tarawneh, A.H.; et al. Ficus plants: State of the art from a phytochemical, pharmacological, and toxicological perspective. Phytother. Res. 2020, in press. [CrossRef]

4. Shang, A.; Liu, H.-Y.; Luo, M.; Xia, Y.; Yang, X.; Li, H.-Y.; Wu, D.-T.; Sun, Q.; Geng, F.; Li, H.-B.; et al. Sweet tea (Lithocarpus polystachyusrehd.) as a new natural source of bioactive dihydrochalcones with multiple health benefits. Crit. Rev. Food Sci. Nutr. 2020, in press. [CrossRef] [PubMed]

5. Shang, A.; Gan, R.-Y.; Xu, X.-Y.; Mao, Q.-Q.; Zhang, P.-Z.; Li, H.-B. Effects and mechanisms of edible and medicinal plants on obesity: An updated review. Crit. Rev. Food Sci. Nutr. 2020, in press. [CrossRef] [PubMed]

6. Gandhi, G.R.; Vasconcelos, A.B.S.; Wu, D.T.; Li, H.B.; Antony, P.J.; Li, H.; Geng, F.; Gurgel, R.Q.; Narain, N.; Gan, R.Y. Citrus flavonoids as promising phytochemicals targeting diabetes and related complications: A systematic review of in vitro and in vivo studies. Nutrients 2020, 12, 2907. [CrossRef] [PubMed]

7. Tang, G.Y.; Meng, X.; Gan, R.Y.; Zhao, C.N.; Liu, Q.; Feng, Y.B.; Li, S.; Wei, X.L.; Atanasov, A.G.; Corke, H.; et al. Health functions and related molecular mechanisms of tea components: An update review. Int. J. Mol. Sci. 2019, 20, 6196. [CrossRef] [PubMed]

8. Li, B.-Y.; Xu, X.-Y.; Gan, R.-Y.; Sun, Q.-C.; Meng, J.-M.; Shang, A.; Mao, Q.-Q.; Li, H.-B. Targeting gut microbiota for the prevention and management of diabetes mellitus by dietary natural products. Foods 2019, 8, 440. [CrossRef]

9. Cao, S.-Y.; Zhao, C.-N.; Xu, X.-Y.; Tang, G.-Y.; Corke, H.; Gan, R.-Y.; Li, H.-B. Dietary plants, gut microbiota, and obesity: Effects and mechanisms. Trends Food Sci. Tech. 2019, 92, 194-204. [CrossRef]

10. Meng, X.; Li, Y.; Li, S.; Gan, R.-Y.; Li, H.-B. Natural products for prevention and treatment of chemical-induced liver injuries. Compr. Rev. Food Sci. Saf. 2018, 17, 472-495. [CrossRef]

11. Meng, X.; Li, S.; Li, Y.; Gan, R.-Y.; Li, H.-B. Gut microbiota's relationship with liver disease and role in hepatoprotection by dietary natural products and probiotics. Nutrients 2018, 10, 1457. [CrossRef]

12. Cheng, J.X.; Zhang, B.D.; Zhu, W.F.; Zhang, C.F.; Qin, Y.M.; Abe, M.; Akihisa, T.; Liu, W.Y.; Feng, F.; Zhang, J. Traditional uses, phytochemistry, and pharmacology of Ficus hispida L.f.: A review. J. Ethnopharmacol. 2020, 248, 112204. [CrossRef]

13. Chaware, G.K.; Kumar, V.; Kumar, S.; Kumar, P. Bioactive compounds, pharmacological activity and food application of Ficus racemosa: A critical review. Int. J. Fruit Sci. 2020, 20, S969-S986. [CrossRef]

14. Hossain, M.A. A review on Ficus sycomorus: A potential indigenous medicinal plant in Oman. J. King Saud Univ. Sci. 2019, 31, 961-965. [CrossRef]

15. Singh, D.; Singh, B.; Goel, R.K. Traditional uses, phytochemistry and pharmacology of Ficus religiosa: A review. J. Ethnopharmacol. 2011, 134, 565-583. [CrossRef] [PubMed]

16. Badgujar, S.B.; Patel, V.V.; Bandivdekar, A.H.; Mahajan, R.T. Traditional uses, phytochemistry and pharmacology of Ficus carica: A review. Pharm. Biol. 2014, 52, 1487-1503. [CrossRef]

17. Mawa, S.; Husain, K.; Jantan, I. Ficus carica L. (Moraceae): Phytochemistry, traditional uses and biological activities. Evid. Based Complementary Altern. Med. 2013, 2013, 974256. [CrossRef] [PubMed]

18. Noronha, N.M.; Ribeiro, G.E.; Ribeiro, I.S.; Marques, M.J.; Coelho, L.F.L.; Chavasco, J.K. Phytochemical profile and antioxidant and antimicrobial activities of hydroethanolic extracts of Ficus pumila. Afr. J. Microbiol. Res. 2014, 8, 2665-2671. [CrossRef]

19. Liao, C.; Kao, C.; Peng, W.; Chang, Y.; Lai, S.; Ho, Y. Analgesic and anti-inflammatory activities of methanol extract of Ficus pumila L. in mice. Evid. Based Complementary Altern. Med. 2012, 2012, 340141. [CrossRef]

20. Tkachenko, H.; Buyun, L.; Terech-Majewska, E.; Osadowski, Z. In vitro antimicrobial activity of ethanolic extracts obtained from Ficus spp. leaves against the fish pathogen Aeromonas hydrophila. Arch. Pol. Fish. 2016, 24, 219-230. [CrossRef]

21. Larbie, C.; Appiah-Opong, R.; Acheampong, F.; Tuffour, I.; Inkabi, S.E. Anti-proliferative effect of Ficus pumila Linn. on human leukemic cell lines. Int. J. Basic. Clin. Pharmacol. 2015, 4, 330-336. [CrossRef]

22. Wu, J.; Chen, M.; Shi, S.; Wang, H.; Li, N.; Su, J.; Liu, R.; Huang, Z.; Jin, H.; Ji, X.; et al. Hypoglycemic effect and mechanism of a pectic polysaccharide with hexenuronic acid from the fruits of Ficus pumila L. in C57BL/KsJdb/db mice. Carbohydr. Polym. 2017, 178, 209-220. [CrossRef] [PubMed]

23. Wu, J.; Xu, Y.; Su, J.; Zhu, B.; Wang, S.; Liu, K.; Wang, H.; Shi, S.; Zhang, Q.; Qin, L.; et al. Roles of gut microbiota and metabolites in a homogalacturonan-type pectic polysaccharide from Ficus pumila Linn. fruits mediated amelioration of obesity. Carbohydr. Polym. 2020, 248, 116780. [CrossRef] [PubMed] 
24. Larbie, C.; Torkornoo, D.; Nyanor, E.; Asibey, O. Evaluation of the hepatoprotective potential of hydroethanolic extract of Ficus pumila L. on CCl4-induced liver damage in rats. Glob. J. Res. Med. Plant Indig. Med. 2016, 5, 217-225.

25. Suzuki, K.; Gonda, K.; Kishimoto, Y.; Katsumoto, Y.; Takenoshita, S. Potential curing and beneficial effects of Ooitabi (Ficus pumila L.) on hypertension and dyslipidaemia in Okinawa. J. Hum. Nutr. Diet. 2020, in press. [CrossRef]

26. Wu, W.; Ji, X.; Wang, Y.; Fang, Y. The extraction technology of total flavonoids from the leaves and receptacle of the inflorescence of Ficus pumila L. J. Plant Resour. Environ. 2000, 9, 55-56.

27. Pistelli, L.; Chiellini, E.E.; Morelli, I. Flavonoids from Ficus pumila. Biochem. Syst. Ecol. 2000, 28, 287-289. [CrossRef]

28. Xiao, W.; Chen, W.; Song, X.; Chen, G.; Zhang, J.; Liu, L.; Han, C. Chemical constituents from the stems of Ficus pumila. Chin. Tradit. Pat. Med. 2015, 37, 1734-1737. [CrossRef]

29. Fan, M.S.; Ye, G.; Huang, C.G. A study on chemical constituents of Ficus pumila L. (In Chinese). Chin. Tradit. Herb. Drugs 2005, 36, 984-986.

30. Abraham, L.C.N.; Masakuni, T.; Isao, H.; Hajime, T. Antioxidant flavonoid glycosides from the leaves of Ficus pumila L. Food Chem. 2008, 109, 415-420. [CrossRef]

31. Trinh, P.T.N.; An, N.H.; An, P.N.; Tri, M.D.; Van Du, C.; Minh, P.N.; Le Thuy, N.T.; Tuan, N.T.; Thoa, V.T.K.; Dung, L.T. A new benzofuran derivative from the leaves of Ficus pumila L. Nat. Prod. Res. 2018, 32, 1648-1652. [CrossRef] [PubMed]

32. Kitajima, J.; Kimizuka, K.; Arai, M.; Tanaka, Y. Constituents of Ficus pumila leaves. Chem. Pharm. Bull. 1998, 46, 1647-1649. [CrossRef]

33. Wang, J.; Qin, J.; Liu, C.; Tang, H. Alpha-Glucosidase and acetylcholinesterase inhibitory potency of extract from rhizome of Ficus pumila L. J. Guangxi Nor. Univ. (Nat. Sci. Edi.) 2017, 35, 69-74. [CrossRef]

34. Xia, A.; Wei, S.; Liao, H. Determination of Catechin in Ficus Pumila Linn. Phar. J. Chin. Peop. Liber. Army 2015, 31, 333-334, 337. [CrossRef]

35. Wei, W.; Fan, C.; Wang, G.; Tang, H.; Wang, Y.; Ye, W. Chemical constituents from Ficus pumila. Chin. Tradit. Herb. Drugs 2014, 45, 615-621. [CrossRef]

36. Kitajima, J.; Kimizuka, K.; Tanaka, Y. New dammarane-type acetylated triterpenoids and their related compounds of Ficus pumila fruit. Chem. Pharm. Bull. 1999, 47, 1138-1140. [CrossRef]

37. Zeng, S.; Han, X.; Li, S. Quantification of the active ingredient quercetin of "Guangdong Wang-bu-liu-xing" by high-performance liquid chromatography with UV detection. J. Chin. Pharm. Sci. 2013, 22, 101-105. [CrossRef]

38. Kitajima, J.; Kimizuka, K.; Tanaka, Y. Three new sesquiterpenoid glucosides of Ficus pumila fruit. Chem. Pharm. Bull. 2000, 48, 77-80. [CrossRef] [PubMed]

39. Juan, E.A.; Rideout, J.A.; Ragasa, C.Y. Bioactive furanocoumarin derivatives from Ficus pumila (Moraceae). Philip. J. Sci. 1997, 126, 143-153.

40. Cai, Y.; Xiao, X.; Song, X.P.; Chen, G.Y.; Yan, L.L.; Han, C.R. Chemical constituents from leaves of Ficus pumila. J. Chin. Med. Mater. 2017, 4, 834-837. [CrossRef]

41. Xiao, W.-L.; Chen, W.-H.; Zhang, J.-Y.; Song, X.-P.; Chen, G.-Y.; Han, C.-R. Ionone-type sesquiterpenoids from the stems of Ficus pumila. Chem. Nat. Compd. 2016, 52, 531-533. [CrossRef]

42. Bai, M.; Cai, Y.; Wu, S.-Y.; Song, X.-P.; Chen, G.-Y.; Zheng, C.-J.; Han, C.-R. A new norisoprenoid from the leaves of Ficus pumila. Nat. Prod. Res. 2019, 33, 1292-1297. [CrossRef] [PubMed]

43. Zhang, F.; Zhang, J.Q.; Kong, L.Y. A study on chemical constituents of Ficus pumila L. Chin. Tradit. Herb. Drugs 2009, 40, 1554-1555. (In Chinese) [CrossRef]

44. Ragasa, C.Y.; Juan, E.; Rideout, J.A. A triterpene from Ficus pumila. J. Asian Nat. Prod. Res. 1999, 1, 269-275. [CrossRef] [PubMed]

45. Tseng, K.F.; Yoa, T.R. Chemical studies on the Chinese drug Pi-Li (Ficus pumila L.). Acta Pharm. Sin. 1965, 12, 577-583.

46. Kitajima, J.; Kimizuka, K.; Tanaka, Y. New sterols and triterpenoids of Ficus pumila fruit. Chem. Pharm. Bull. 1998, 46, 1408-1411. [CrossRef]

47. Yao, M.J.; Pei, J.R. Study on supercritical carbon dioxide extraction technology of Ficus pumila L. seed oiL. Food Sci. 2008, 29, 247-250.

48. Meng, X.; Zhou, J.; Zhao, C.N.; Gan, R.Y.; Li, H.B. Health benefits and molecular mechanisms of resveratrol: A narrative review. Foods 2020, 9, 340. [CrossRef]

49. Farha, A.K.; Gan, R.Y.; Li, H.B.; Wu, D.T.; Atanasov, A.G.; Gul, K.; Zhang, J.R.; Yang, Q.Q.; Corke, H. The anticancer potential of the dietary polyphenol rutin: Current status, challenges, and perspectives. Crit. Rev. Food Sci. Nutr. 2020, in press. [CrossRef]

50. Xu, X.Y.; Meng, X.; Li, S.; Gan, R.Y.; Li, Y.; Li, H.B. Bioactivity, health benefits, and related molecular mechanisms of curcumin: Current progress, challenges, and perspectives. Nutrients 2018, 10, 1553. [CrossRef]

51. Gan, R.Y.; Li, H.B.; Sui, Z.Q.; Corke, H. Absorption, metabolism, anti-cancer effect and molecular targets of epigallocatechin gallate (EGCG): An updated review. Crit. Rev. Food Sci. Nutr. 2018, 58, 924-941. [CrossRef] [PubMed]

52. Xu, X.Y.; Zhao, C.N.; Cao, S.Y.; Tang, G.Y.; Gan, R.Y.; Li, H.B. Effects and mechanisms of tea for the prevention and management of cancers: An updated review. Crit. Rev. Food Sci. Nutr. 2020, 60, 1693-1705. [CrossRef] [PubMed]

53. Ge, J.; Sun, C.X.; Corke, H.; Gul, K.; Gan, R.Y.; Fang, Y.P. The health benefits, functional properties, modifications, and applications of pea (Pisum sativum L.) protein: Current status, challenges, and perspectives. Compr. Rev. Food Sci. Saf. 2020, 19, 1835-1876. [CrossRef] [PubMed] 
54. Shang, A.; Cao, S.Y.; Xu, X.Y.; Gan, R.Y.; Tang, G.Y.; Corke, H.; Mavumengwana, V.; Li, H.B. Bioactive compounds and biological functions of garlic (Allium sativum L.). Foods 2019, 8, 246. [CrossRef]

55. Mao, Q.Q.; Xu, X.Y.; Cao, S.Y.; Gan, R.Y.; Corke, H.; Beta, T.; Li, H.B. Bioactive compounds and bioactivities of ginger (Zingiber officinale Roscoe). Foods 2019, 8, 185. [CrossRef]

56. Wang, J.J.; Li, J.; Chen, B.H.; Lian, J.R.; Li, L. Prilimilary study on antioxidant activity of ethanol extracts from Ficus pumila L. fruit. J. Fujian Nor. Univ. (Nat. Sci.) 2009, 25, 110-114.

57. Tang, H.; Guo, L.; Li, L.; Zhong, S.; Deng, S. Study on antioxidant activity of extract from stem and leaves of Ficus pumila L. Sci. Technol. Food Ind. 2012, 33, 166-169.

58. Zeng, C.; Meiyuan, L.U.; Tingting, M.O.; Bing, W.U.; Lan, Q. Experimental study on the anti-inflammatory effect of Ficus pumila L. Med. Plant 2020, 11, 26-29.

59. Mao, C.N.; Tan, Y.F.; Yang, W.L.; Liu, M.S. Anti-inflammatory effects of different extracts of Ficus pumila. Lishizhen Med. Mater. Med. Res. 2011, 22, 1596-1597.

60. Mao, C.; Tan, Y.; Yan, H.; Luo, H. Research of anti-inflammatory activity of alcohol extraction in Ficus pumila L medicinaL. Chin. Med. Pharm. 2012, 2, 37-38, 50.

61. Wu, J.; Xu, Y.; Zhu, B.; Liu, K.; Wang, S.; Sheng, Y.; Wang, H.; Shi, S.; Zhang, Q.; Wang, S.; et al. Characterization of an arabinogalactan from the fruit hulls of Ficus pumila Linn. and its immunomodulatory effect. J. Funct. Foods 2020, 73. [CrossRef]

62. Mao, C.N.; Yang, W.L. Study on bacteriostasis in different extracts from Ficus pumila L. Sci. Technol. Innov. Her. 2012, $24,2-3$.

63. Wan, Q.F.; Wu, L.; Yang, M.L.; Rui, M.A.; Liang, J.; Gu, L.G. Effect of quercetin on caspase-3 of A549 cell induced by influenza virus H1N1. Chin. J. Inf. Tradit. Chin. Med. 2011, 18, 42-44.

64. Ramcharan, G.; Clement, Y.N.; Maxwell, A.R. Cytotoxic activity of selected West Indian medicinal plants against a human leukaemia cell line. West Indian Med. J. 2010, 59, 597-601. [PubMed]

65. Dureshahwar, K.; Mubashir, M.; Upaganlwar, A.; Sangshetti, J.N.; Upasani, C.D.; Une, H.D. Quantitative assessment of tactile allodynia and protective effects of flavonoids of Ficus carica Lam. leaves in diabetic neuropathy. Pharmacogn. Mag. 2019, 15, 128-134. [CrossRef]

66. Arunachalam, K.; Parimelazhagan, T. Antidiabetic activity of Ficus amplissima Smith. bark extract in streptozotocin induced diabetic rats. J. Ethnopharmacol. 2013, 147, 302-310. [CrossRef]

67. Choo, C.Y.; Sulong, N.Y.; Man, F.; Wong, T.W. Vitexin and isovitexin from the leaves of Ficus deltoidea with in-vivo alphaglucosidase inhibition. J. Ethnopharmacol. 2012, 142, 776-781. [CrossRef]

68. Liang, R.-H.; Chen, J.; Liu, W.; Liu, C.-M.; Yu, W.; Yuan, M.; Zhou, X.-Q. Extraction, characterization and spontaneous gel-forming property of pectin from creeping fig (Ficus pumila Linn.) seeds. Carbohydr. Polym. 2012, 87, 76-83. [CrossRef]

69. Lu, J.; Su, X.; Fang, G.; Liu, X. Pectin ameliorates the impact of capsaicin on intestinal fermentation environment. Food Sci. 2013, $34,273-277$.

70. Lu, H.; Su, X.; Tang, Y.; Liu, X. Effect of pectin from Ficus pumila L. seeds on capsaicin-induced intestinal injury in ovariectomized rats. Food Sci. 2013, 34, 293-297.

71. Tang, Y.; Gui, Y.; Ren, W.; Peng, L.; Liu, X. Effect of water-based extraction of pectin from Ficus pumila L. seeds on bowel health in ovariectomized rats. Sci. Tech. Food Ind. 2013, 34, 347-351, 356.

72. Li, B.; Lu, H.; Tang, Y.; Qin, X.; Liu, X. Effect of pectin from Ficus pumila L. seeds on lipid metabolism and cecum environment in castrated rats fed high fat diet. Food Sci. 2015, 36, 183-188.

73. El-hawary, S.S.; Ali, Z.Y.; Younis, I.Y. Hepatoprotective potential of standardized Ficus species in intrahepatic cholestasis rat model: Involvement of nuclear factor-kappa B, and Farnesoid X receptor signaling pathways. J. Ethnopharmacol. 2019, 231, 262-274. [CrossRef] [PubMed]

74. Awad, N.E.; Hamed, M.A.; Seida, A.A.; Elbatanony, M.M. Efficacy of Ficus spp. on renal injury induced by hypercholesterolaemia. Nat. Prod. Res. 2012, 26, 1561-1564. [CrossRef] [PubMed]

75. Irene, I.I.; Iheanacho, U.A. Acute effect of administration of ethanol extracts of Ficus exasperata vahl on kidney function in albino rats. J. Med. Plants Res. 2007, 1, 27-29. [CrossRef]

76. Mandal, S.C.; Maity, T.K.; Das, J.; Pal, M.; Saha, B.P. Hepatoprotective activity of Ficus racemosa leaf extract on liver damage caused by carbon tetrachloride in rats. Phytother. Res. 1999, 13, 430-432. [CrossRef]

77. Larbie, C.; Siaw, P.; Zon, S.; Appiah-Kubi, K. Hydroethanolic extracts of Ficus pumila Linn. is protective against gentamicininduced kidney damage in rats. J. Adv. Med. Pharm. Sci. 2018, 17, 1-8. [CrossRef]

78. Ke, Z.; Song, G.; Ma, J.; Gao, D.; Xie, Z.; Zhang, X. Comparative study of effects on invigorating the kidney and strengthened yang of two sections of fruits from Ficus pumila L. J. Guangdong Pharm. Coll. 2011, 27, 74-76.

79. Ying, N.; Meina, Z.; Wei, Z.; Physiology, D.O. Protective effects of $\alpha$-Linolenic acid against ischemic heart failure and the underlying mechanisms: Inhibition of NLRP3 in the early stage of ischemia. Immunol. J. 2018, 34, 207-213.

80. Wang, H.G.; Bo, Q.X.; Wang, Z.W. Mechanism of linolenic acid to improve vascular endothelial cell injury in elderly patients with hypertension. Chin. J. Immunol. 2016, 32, 1678-1681, 1688.

81. He, X.-G.; Fan, J.-B.; Liu, H.-J.; Xia, N. Anti-hyperprolactinemic effect of Ficus pumila Linn extract in rats. Trop. J. Pharm. Res. 2016, 15, 1459-1463. [CrossRef]

82. Zhang, L.; Feng, Y.; Liu, X.; Chen, Z. Effect of pectin from Ficus pumila L. seeds on mineral absorption in ovariectomized rats. Food Sci. 2012, 33, 261-265. 
83. Wu, W.S.; Fang, Y.L. A study on nutritive composition of the achenia of Ficus pumila L. J. Nat. Resour. 1999, 2, 51-55.

84. Liang, R.H.; Bi, S.T.; Liu, C.M.; Liu, W.; Liu, W.L.; Zhang, Z.Q. Study on gelling properties of Ficus pumila Linn. seed pectin. Food Sci. 2008, 29, 110-113.

85. Peng, L.; Lv, Y. Study on the development of carrageenan jelly by Ficus pumila L. var seed gelatin. Sci. Tech. Food Ind. 2004, 25, 90-91.

86. Kang, D. The developing of compound beverage of enriched selenium golden mushroom and Ficus Pumila L.var juice. Food Sci. 2003, 24, 91-92.

87. Lai, W.; Tan, Y.; Yang, W.; Zhang, J.; Liu, M. Study on the acute toxicity of the aqueous extract of Polygonum hydropiper, Ficus pumila and Evodia lepta. J. Hainan Med. Coll. 2010, 16, 411-412.

88. Tian, X.; Chen, L.; Zhou, R.; Zheng, J. Effects of different forms of stem plants on soil and water conservation and nutrient retention in karst areas. Res. Soil Water Cons. 2014, 21, 64-68, 73.

89. Chen, C.F.; Kang, S.F. Effects of substrates and plant species on water quality of extensive green roofs. Appl. Ecol. Environ. Res. 2016, 14, 77-91. [CrossRef]

90. Li, G.; Ding, S.; Zhou, X. Ecological effects of the twelve species for vertical greening in South China. J. South China Agric. Univ. 2008, 29, 11-15.

91. Takahashi, M.; Kohama, S.; Shigeto, J.; Hase, Y.; Tanaka, A.; Morikawa, H. Mutants of Ficus pumila produced by ion beam irradiation with an improved ability to uptake and assimilate atmospheric nitrogen dioxide. Int. J. Phyto. 2012, 14, $275-281$. [CrossRef] [PubMed]

92. Corlett, R.T. Figs (Ficus, Moraceae) in urban Hong Kong, south China. Biotropica 2006, 38, 116-121. [CrossRef]

93. Cai, Y.; Song, Y. Adaptive ecology of lianas in an evergreen broad-leaved forest of Tiantong National Forest Park, Zhejiang: II. Climbing capacity and climbing efficiency. Acta Phyto. Sin. 2005, 29, 386-393.

94. Xia, H.; Cai, X.; Peng, C. Comparison of five lianas for vertical greening. Acta Pratacul. Sin. 2007, 16, 93-100.

95. Wang, J.; Wang, L.; Han, G. Tolerance and physiological response of four lianas to soil manganese contamination. Acta Botan. Bor. Occid. Sin. 2015, 35, 1604-1611.

96. Miklaszewska, K. Figowiec (fikus) pnacy (Ficus pumila, Ficus repens): Protection of home pot plants (27). Ochr. Rosl. 2002, 46, 30-31.

97. Creech, J.L. Evergreen vines from Japan are intriguing choices for warm climates. Asian natives for American landscapes. Amer. Nurs. 1986, 163, 58-64.

98. Wu, Y.X.; Tao, D.H.; Deng, P.Y. Problems and countermeasures of using vines for rocky desertification controL. S. China For. Sci. 2015, 43, 50-55.

99. Sahin, E.K. Reproduction of Ficus pumila L. (climbing fig) with tissue culture. Anadolu 2018, 28, 52-55.

100. Jiang, A.F.; Tian, D.L.; Tan, X.F.; Zhang, D.Q.; Zeng, Y.L.; Yang, W. Tissue culture of stem segment and plantlet regeneration of Ficus pumila L. J. Cent. S. Univ. For. Tech. 2007, 27, 10-13. 